PontifícIA UNIVERSidADE CATÓLICA do RIO DE JANEIRO

\title{
Home Bias e a diversificação geográfica
}

Trabalho de Conclusão de Curso

\section{José Victor Monteiro Vaz Ferreira}

Centro de Ciências Sociais- CCS Departamento de Administração Graduação em Administração de Empresas 
José Victor Monteiro Vaz Ferreira

\section{Home Bias e a diversificação geográfica}

Trabalho de conclusão de curso

Trabalho de Conclusão de Curso, apresentado ao programa de graduação em Administração da PUC-Rio como requisito parcial para a obtenção do título de graduação em Administração.

Orientador: André Cabús Klötzle

Rio de Janeiro, junho de 2020 


\section{Resumo}

FERREIRA, José Victor Monteiro Vaz. Home Bias e a diversificação geográfica. Rio de Janeiro, 2020. 44 p. Trabalho de Conclusão de Curso - Departamento de Administração. Pontifícia Universidade Católica do Rio de Janeiro.

O estudo das carteiras desenvolvido neste trabalho tem o objetivo de mostrar as diferenças entre os efeitos da diversificação geográfica em relação à diversificação setorial, através da covariância, do coeficiente de correlação e em termos de risco/retorno. E, também, busca-se entender porque os investidores da bolsa de valores B3 evitam diversificar geograficamente e o que eles sentem sobre isso. Juntando ambos os resultados, caso sejam comprovados, podemos demostrar a ocorrência do Home Bias e que esse fenômeno provoca um comportamento irracional no investidor, que aplica seus recursos apenas na bolsa de valores brasileira.

Palavras-Chave: Diversificação, Covariância, Correlação, Risco, Retorno, Home Bias.

\section{Abstract}

FERREIRA, José Victor Monteiro Vaz. Home Bias and the geographical diversification. Rio de Janeiro, 2020. 44 p. Final Thesis - Business Department. Pontifícia Universidade Católica do Rio de Janeiro.

The portfolio study developed in this work aims to show the differences between the effects of geographical diversification in relation to sectoral diversification, through their covariance, correlation and risk/return analysis. In addition, we try to understand why B3 stock market investors avoid to geographically diversify their investments and how they feel about it. With both results - if proven - we can demonstrate Home Bias occurrence and that this phenomenon induces an irrational behavior on investors, that apply their resources at Brazilian financial markets only.

Keywords: Diversification, Covariance, Correlation, Risk, Return, Home Bias. 


\section{Conteúdo}

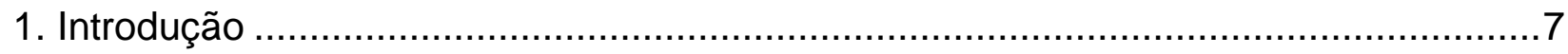

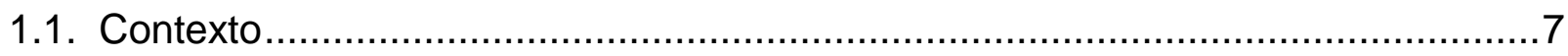

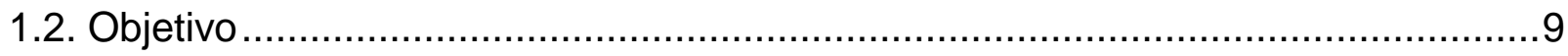

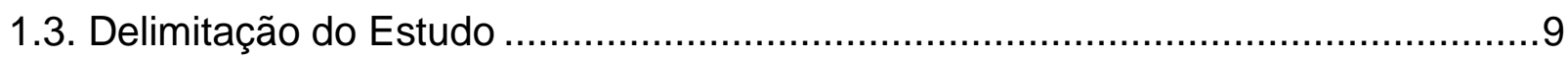

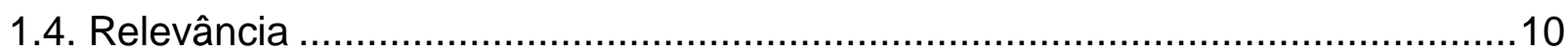

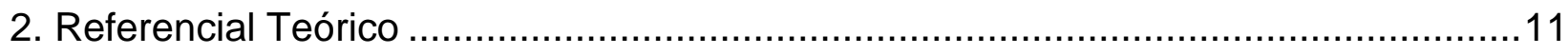

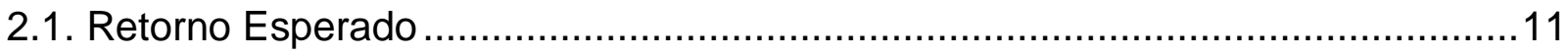

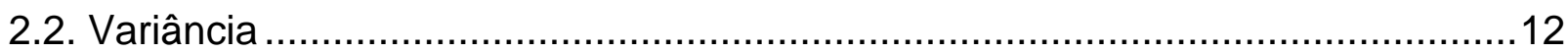

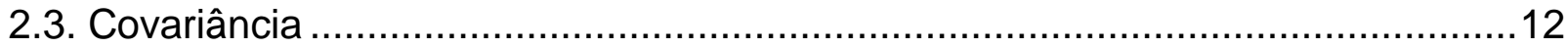

2.4. Coeficiente de Correlação........................................................................13

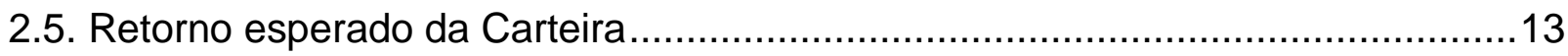

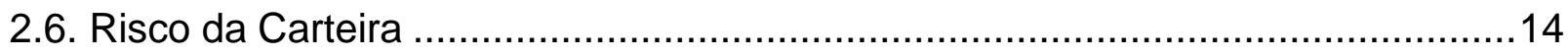

2.7. Risco Sistemático x Risco não Sistemático ......................................................14

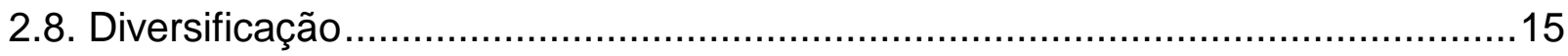

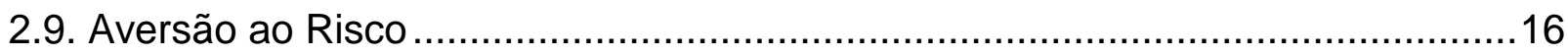

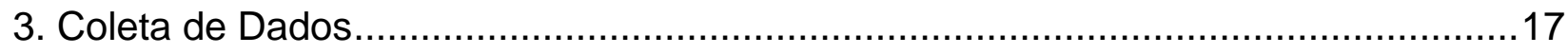

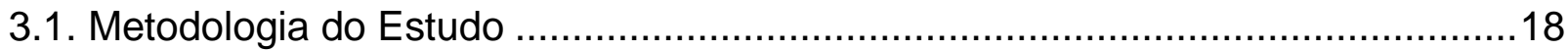

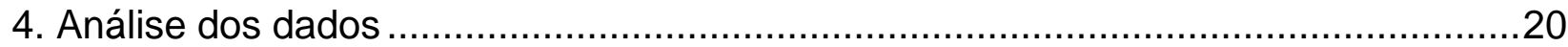

4.1. Teoria da Carteira, Covariância e Correlação ...................................................20

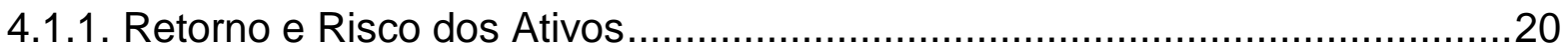

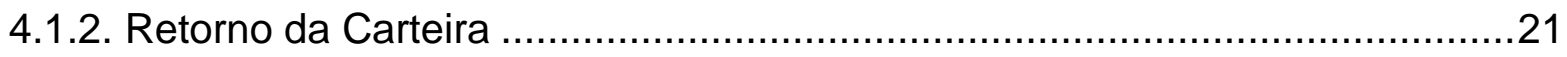



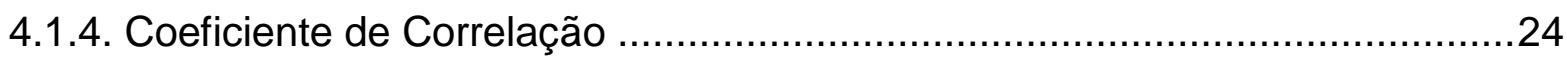

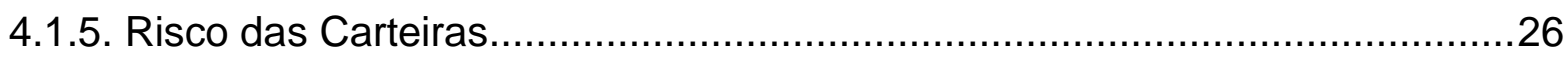






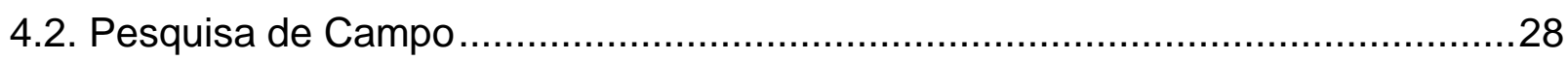

4.2.1. Aceitação de risco $x$ Vontade de Investir em Bolsas estrangeiras ..................28

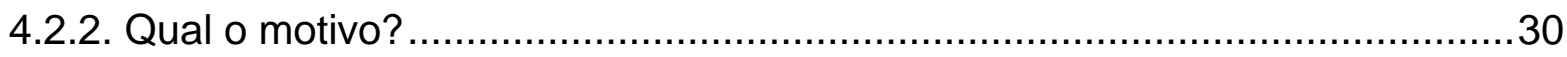

4.2.3. Qual você acha que é ou pode ser a maior dificuldade em investir em bolsas estrangeiras?

4.2.4. Grau de importância das razões que levam os investidores a evitar a compra de ações de bolsas estrangeiras ......................................................................32

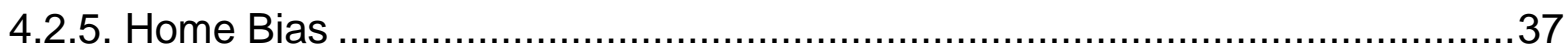

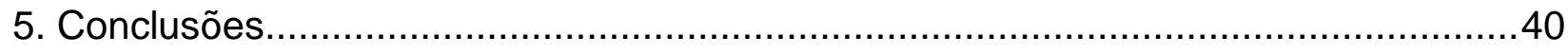

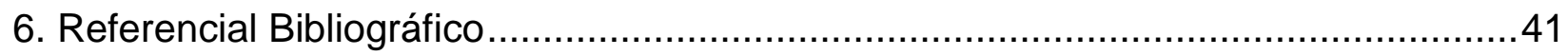

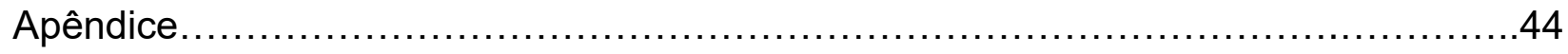

\section{Lista de Figuras}

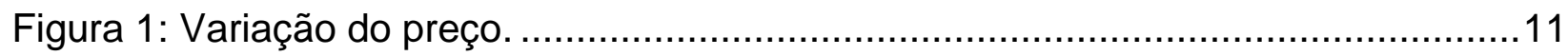

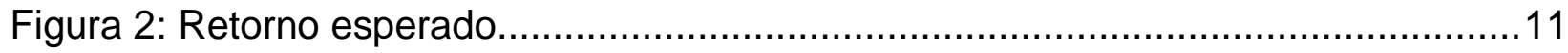

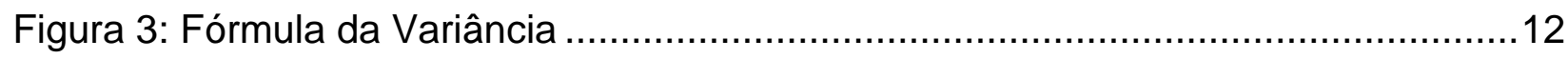

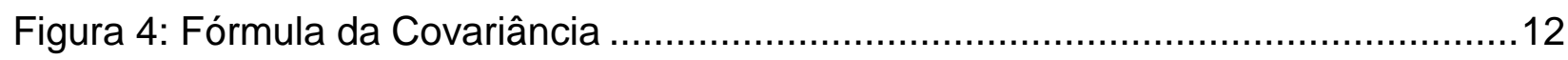

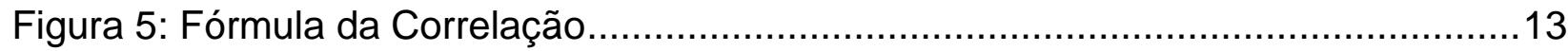

Figura 6: Fórmula do Retorno Esperado da Carteira ..............................................13

Figura 7: Fórmula do Risco da Carteira ...............................................................

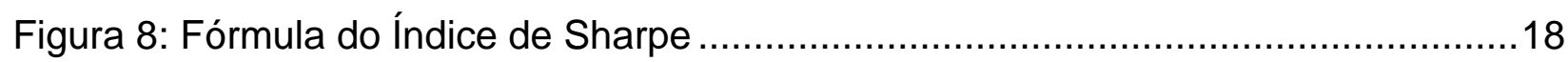

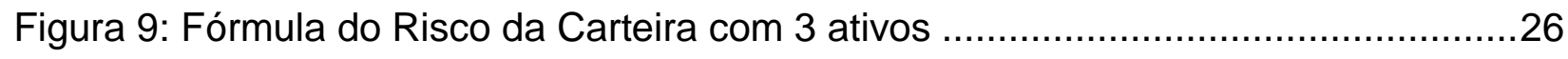

Figura 10: Fórmula com Coeficiente de Correlação (2 ativos) ….................................27 


\section{Lista de Tabelas}

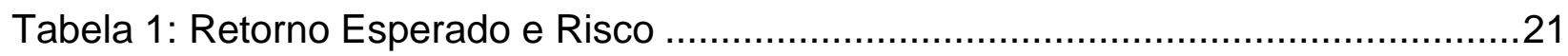

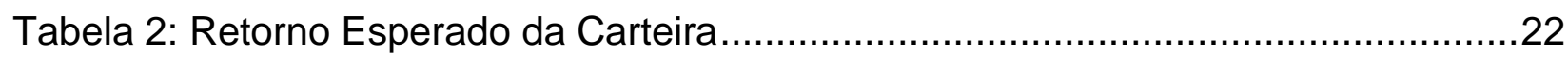

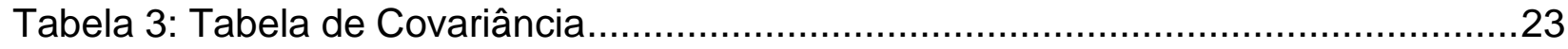

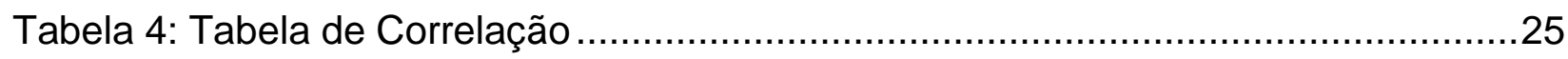

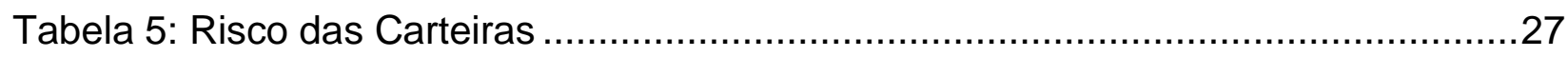

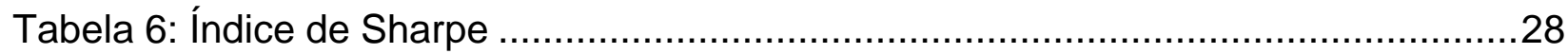

Tabela 7: Desconforto x Vontade de investir em Bolsas Estrangeiras ...........................38

\section{Lista de Gráficos}

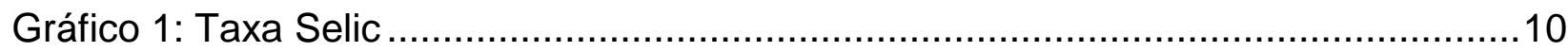

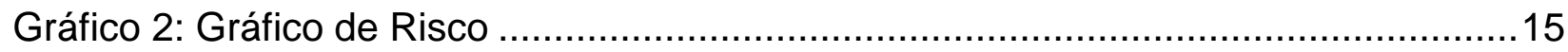

Gráfico 3: Vontade de Investir x Aversão a Risco (\%)..............................................29

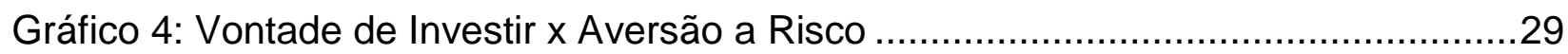

Gráfico 5: Importância das Diferenças Culturais ao Investir .......................................33

Gráfico 6: Importância das Diferenças Línguísticas ao Investir .....................................34

Gráfico 7: Importância de usar/conhecer o serviço ou produto ao Investir...................35

Gráfico 8: Importância da Burocracia na decisão de compra de ações .........................36

Gráfico 9: Importância de estar próximo à Empresa ao Investir ....................................36

Gráfico 10: Desconforto em Investir em Bolsas Estrangeiras ......................................37

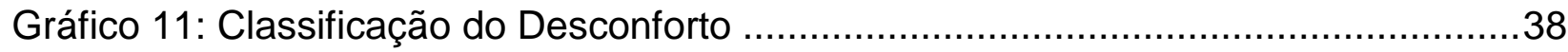




\section{Introdução}

\subsection{Contexto}

Muito se é discutido, pelos profissionais atuantes no mercado de capitais, sobre a importância da diversificação na hora de montar uma carteira de investimentos. É sabido que ações são pequenos pedaços de uma empresa. Quando adquirimos uma ação, esperamos que a empresa tenha resultados positivos, assim aumentando seu valor de mercado. Ao mesmo tempo, estamos assumindo o risco de isso não ocorrer. Segundo Damadoran (2002, p.56), o risco surge quando retornos esperados de determinadas ações sofre variações.

De acordo com o site Pro Educacional (2018), existem dois tipos de risco nesse tipo de investimento abordado acima: o risco sistemático, o risco que não pode ser diversificado. E o risco não sistemático, também conhecido como único ou específico, que pode ser diversificado. Este que por sua vez, tem um papel de destaque neste trabalho, dado sua capacidade de diminuir os riscos de uma carteira, deixando-a mais eficiente.

Segundo a SunoResearch (2017), a diversificação de uma carteira de ações pode ser por: setores de uma economia, ou por países (geográfica). Assim, conseguimos montar carteiras de ativos com maiores retornos e menores riscos. Como o foco do estudo são ações, iremos estudar apenas essas diversificações, por setores e geográfica. Porém, há como diversificar comprando outro tipo de ativos, como: fundos, títulos, opções, Imóveis, e até obras de arte.

Em concordância com Frank (2018), as pessoas tendem a ter maior afinidade por investimentos do seu próprio país. Esse viés mencionado acima é denominado como Home Bias. Ou seja, elas diversificam mais por setores do que por país.

Segundo Silva et al. (2020), grande parte dos investidores não investem ou investem apenas uma pequena parte dos seus recursos em ativos internacionais. Eles concentram suas aplicações exclusivamente ou quase que exclusivamente no mercado doméstico de capitais. Assim, destacando o fenômeno conhecido por Home Bias. Alguns estudos apontam que o "Home Bias" ocorre por conta de alguns fatores comportamentais como: a aversão ao risco, procura dos investidores pela 
familiaridade e a falta de conhecimento dos mercados internacionais.

Mas será que essas pessoas não estão perdendo a oportunidade de investimentos melhores e mais seguros? Segundo Ricardo Coelho (2008), ações de empresas negociadas em diferentes bolsas costumam ter correlações baixas. Logo quando incluímos ações da bolsa de Nova York, por exemplo, em uma carteira de uma outra região geográfica, esta carteira fica mais diversificada. Dado que a correlação é a relação entre as variações no preço de duas ações, e as variações de empresas de diferentes países não possuem muitas relações.

Em conformidade com Mark Grinblatt (2001), podemos constatar três fatores que levam ao viés relatado acima: distância, língua e cultura. Exemplificando com o caso Finlandês, que é um país que possui duas línguas oficiais: Filandês e o Sueco. Quem tem como principal língua o Finlandês, prefere CEOs Filandeses e empresas que publicam seus relatórios na sua língua. Quem tem como principal língua o Sueco, prefere CEOs Suecos e empresas que publicam seus relatórios na sua língua.

Ainda, segundo Frank (2018), há outros fatores como: otimismo sobre o mercado doméstico, conhecimento da marca e informações vantajosas. Por isso, pessoas têm "medo" de investir em empresas estrangeiras. A maior capacidade de monitoramento e maior conhecimento de uma empresa; acreditar na economia do seu próprio país; e ser usuário da marca, gostar dos produtos ou serviços que a empresa oferece, faz com que investidores tomem ações irracionais na hora de montar sua carteira.

Podemos clarear estes casos usando um outro viés do comportamento humano chamado self-preservation heuristic, que ressalta o evento das pessoas tomarem decisões não racionais por conta da familiaridade, de acordo com Frank (2018). O fato de o investidor conhecer melhor o mercado e a empresa faz com que ele se sinta mais confortável para investir em ações locais.

Trazendo um contraponto ao estudo e indo de acordo com esse comportamento, "gestores de fundos ganham em média $2.67 \%$ a mais por ano, comprando ações de empresas locais, enquanto ações de empresas locais evitadas têm um desempenho abaixo das outras ações em 3\%". (Frank, 2018) 
Logo, existe uma lógica por trás da falta de diversificação geográfica. Mas será que todo esse contexto pode ser por conta de uma falta de competência dos gestores, que não estão observando as oportunidades de serem mais eficientes?

Desta forma, a pergunta que norteará esse estudo é quais fatores levam os investidores brasileiros a evitarem a compra de ativos estrangeiros, contando que a diversificação geográfica pode agregar benefícios a uma carteira de ações?

\subsection{Objetivo}

O objetivo do estudo é constatar as diferenças entre a diversificação setorial e a geográfica para o resultado de uma carteira de ativos. Assim, mostrando para os investidores brasileiros que eles estão perdendo oportunidades de investimentos, que poderiam acarretar em maiores retornos com menores riscos. Pois estes possuem a tendência de evitar a compra de ações de empresas estrangeiras.

Além disso, queremos buscar entender o porquê dessas pessoas estarem evitando esse tipo de compra. E optando por diversificar suas carteiras com ações apenas nacionais.

\subsection{Delimitação do Estudo}

A delimitação do estudo será realizada da seguinte forma: escolheremos aleatoriamente 10 empresas de diferentes setores com ações negociadas no Ibovespa e 10 empresas varejistas - mesmo setor - com ações negociadas em diferentes bolsas do mundo. Estas 20 empresas apenas necessitam ter capital aberto desde o ano de 2015, e que o valor das suas ações tenha aumentado do último dia de pregão de Janeiro de 2015 até o último dia de pregão de Dezembro de 2019.

Após a escolha, faremos 3 carteiras com esses ativos: uma apenas com empresas nacionais diversificada somente por setores da economia; outra com empresas de diferentes bolsas, porém do mesmo setor (varejo); e uma terceira com todos os 20 ativos. Vale ressaltar que o estudo não considerará o câmbio, logo as duas últimas carteiras mencionadas estarão hedgeadas dos efeitos da variação cambial entre países. 
Dessa forma, será possível mostrar os benefícios das diferentes diversificações - tanto a por setores, quanto a geográfica - e compará-los. A análise dos preços das ações será feita mensalmente, de Janeiro de 2015 até Dezembro de 2019. E para efeito de comparações entre a carteiras, usaremos a Taxa Selic do final de 2019 (4,5\%) como taxa livre de risco.

\section{Gráfico 1: Taxa Selic}

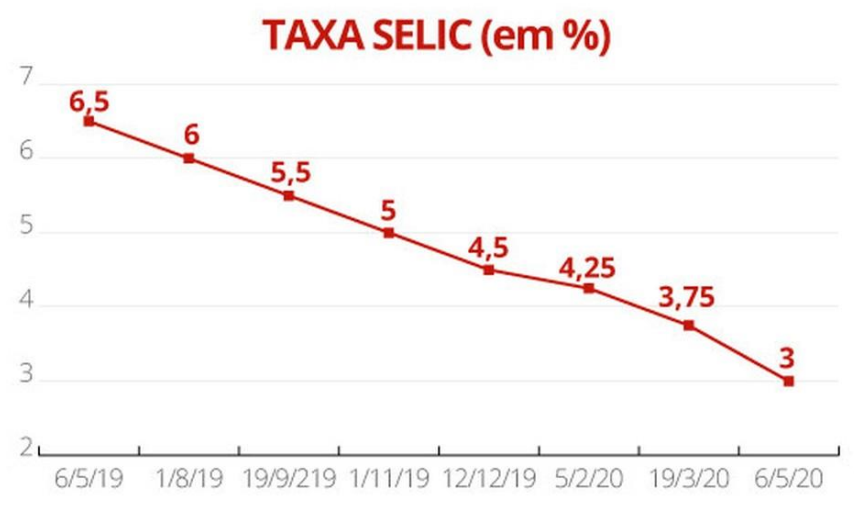

Fonte: G1 (2020).

Também serão realizadas entrevistas com potenciais investidores. Para estas entrevistas, será feito um funil para que apenas pessoas que investem em ações comercializadas na B3 (bolsa brasileira) respondam as perguntas.

\subsection{Relevância}

Esse estudo auxiliará e encorajará investidores brasileiros a criarem suas carteiras de ativos de forma mais diversificada, visando mostrar que os prós da diversificação geográfica são maiores que os contras, e dando a eles mais oportunidades de proteção dos seus investimentos.

Além disso, estes investidores poderão usar os resultados do estudo para abrir a mente em relação a investir capital no exterior, e assim conseguir melhores retornos com menos riscos. 


\section{Referencial Teórico}

\subsection{Retorno Esperado}

O retorno esperado trata-se do retorno que alguém espera de uma ação para o próximo período. É claro que, sendo apenas uma expectativa, o retorno observado pode ser maior ou menor. Essa expectativa pode ser simplesmente 0 retorno médio por período que um título obteve no passado. Outras possibilidades seriam a expectativa ser baseada em uma análise detalhada das perspectivas da empresa, um modelo computacional ou informações privilegiadas (informações internas). (Ross, 2009)

O retorno esperado são as médias das variações dos preços das ações. Para avaliarmos da melhor forma cinco anos mensalmente, uma média geométrica deixaria o resultado mais perto do provável, pois as variações negativas podem mascarar o resultado. Logo, pegaremos o preço do ativo no período t, dividiremos pelo preço no período t-1 (mês anterior) para acharmos as variações. Dessa forma, podemos realizar a média, multiplicando todos os resultados e fazendo a raiz da quantidade de valores multiplicados. Para que assim possamos achar o retorno esperado.

\section{Figura 1: Variação do preço}

$$
R=((P t / P t-1)-1) \times 100
$$

Fonte: Elaboração própria (2020).

Figura 2: Retorno esperado

$$
\bar{R}_{G}=\left[\left(1+R_{1}\right) \times\left(1+R_{2}\right) \times \ldots \times(1+R n)\right]^{\frac{1}{n}}-1
$$

Onde $R_{i}$ corresponde à taxa de retorno no período i e $R \quad{ }_{G} \circ$ percentual médio de retorno de uma determinada variável

Fonte: MBA em gestão de empreendimentos turísticos. UFF (2014). 


\subsection{Variância}

"Variância e desvio padrão: Há muitas maneiras de avaliar a volatilidade do retorno de um título. Uma das mais comuns é por meio da variância, que é uma medida ao quadrado dos desvios dos retornos de um título em relação a seu retorno esperado. O desvio padrão é a raiz quadrada da variância." (Ross, 2019)

O cálculo da variância será realizado para o cálculo do desvio padrão, ou seja, o risco da ação, e para o cálculo da correlação entre os ativos.

\section{Figura 3: Fórmula da Variância}

$$
s^{2}=\frac{\sum_{i=1}^{n}\left(X_{i}-\bar{X}\right)^{2}}{n-1}
$$

Fonte: Ross (2009).

\subsection{Covariância}

"Covariância e correlação: Os retornos de títulos individuais são relacionados uns aos outros. A covariância é uma estatística que mede a interrelação entre os retornos de dois títulos. Como alternativa, essa inter-relação pode ser apresentada em termos da correlação entre os dois títulos. A covariância e a correlação são elementos fundamentais para que se compreenda o coeficiente beta." (Ross, 2009)

A covariância é a média da multiplicação do "Retorno menos o Retorno esperado" de dois ativos, ela serve para medir posteriormente a correlação. Vale ressaltar que essa fórmula retirada de Ross (2009) é equivalente à covariância no período "t". Como vamos avaliar cinco anos mensalmente, o cálculo da covariância abrange o período de 60 meses.

\section{Figura 4: Fórmula da Covariância}

$$
\operatorname{Cov}\left(R_{A}, R_{B}\right)=\text { Valor esperado de }\left[\left(R_{A t}-\bar{R}_{A}\right)\left(R_{B t}-\bar{R}_{B}\right)\right]
$$

\section{Fonte: Ross (2009).}




\subsection{Coeficiente de Correlação}

A correlação é calculada a partir da covariância entre dois ativos, divididos pela multiplicação dos desvios padrões dos mesmos. Ela está em um intervalo entre um e menos um, e é usada para calcular o risco de uma carteira. Quanto menor for a correlação de dois ativos, mais vantajoso é ter ambos numa carteira, pois isso significa que eles variam seguindo padrões diferentes. Logo, quando um aumenta, o outro diminui, e vice-versa. Dessa forma, o risco de ambos caírem diminui, reduzindo o risco da carteira.

Segundo Ross (2002), se houver uma relação direta entre o retorno de dois ativos, sua covariância será positiva; ao contrário, se houver uma relação inversa, a covariância será negativa. Existe ainda o caso de não haver relação entre os dois ativos, onde a covariância deverá ser nula, ou igual a zero.

Figura 5: Fórmula da Correlação

$$
\operatorname{Corr}\left(R_{A}, R_{B}\right)=\frac{\operatorname{Cov}\left(R_{A}, R_{B}\right)}{\sigma_{A} \times \sigma_{B}}
$$

Fonte: Ross (2009).

\subsection{Retorno esperado da Carteira}

"O retorno esperado de uma carteira é uma média ponderada dos retornos esperados dos títulos individuais." (Ross, 2009)

Seja $X_{A}$ e $X_{B}$ a quantidade percentual de recursos investidos na ação $A$ e a quantidade percentual de recursos investidos na ação $B$, respectivamente, dada uma carteira com duas ações, onde $\overline{\mathrm{R}}$ representa seus retornos. $O$ retorno esperado, então, será:

Figura 6: Fórmula do Retorno Esperado da Carteira

$$
\text { Retorno esperado da carteira }=X_{A} \bar{R}_{A}+X_{B} \bar{R}_{B}
$$

Fonte: Ross (2009). 


\subsection{Risco da Carteira}

"A variância de uma carteira depende das duas variâncias dos títulos individuais e da covariância entre os dois títulos. A variância de um título mede a variabilidade do retorno de um título individual. A covariância mede a relação entre os retornos dos dois títulos. Dadas as variâncias dos títulos individuais, uma relação ou covariância positiva entre os dois títulos aumenta a variância de toda a carteira. No entanto, uma relação ou covariância negativa entre os dois títulos diminui a variância de toda a carteira. Esse resultado significativo parece estar de acordo com o senso comum." (Ross, 2009)

Portanto, quanto mais a covariância for negativa, menor é o risco da carteira com ambas as ações. Quanto maior for a covariância, maior é o risco da carteira. Vale ressaltar que na fórmula abaixo, $X_{A}$ e $X_{B}$ continuam sendo a quantidade percentual de recursos investidos na ação $A$ e a quantidade percentual de recursos investidos na ação $B$, respectivamente, dada uma carteira com duas ações.

Figura 7: Fórmula do Risco da Carteira

$$
\sigma_{\text {CARTERA }}^{2}=X_{A}^{2} \cdot \operatorname{Var}_{A}+X_{B}^{2} \cdot \operatorname{Var}_{B}+2 \cdot X_{A} \cdot X_{B} \cdot \operatorname{Cov}(A, B)
$$

Fonte: Top Invest - Risco da carteira (2019).

\subsection{Risco Sistemático x Risco não Sistemático}

De acordo com Ross (2002), "um risco sistemático é qualquer risco que afeta um grande número de ativos, cada um com maior ou menor intensidade. Um risco não sistemático é um risco que afeta especificamente um único ativo ou um pequeno grupo de ativos."

Podemos colocar que existem dois tipos de risco quando realizamos investimentos em ações: o risco sistemático, que é o risco que não pode ser diversificado. Ou seja, mesmo montando carteiras com ações com baixas correlações, esse risco não desaparece. Por exemplo, um colapso no mercado 
financeiro, ou uma mudanças na taxa de juros ou câmbio, algo que afeta a economia, e assim todas as empresas de uma forma geral.

$\mathrm{E}$ existe o risco não sistemático, também conhecido como único ou específico, que pode ser diversificado. Ou seja, ele pode ser reduzido e até zerado caso compremos diversas ações com baixas correlações. Este, por sua vez, está relacionado a um setor ou empresa específica.

\section{Gráfico 2: Gráfico de Risco}

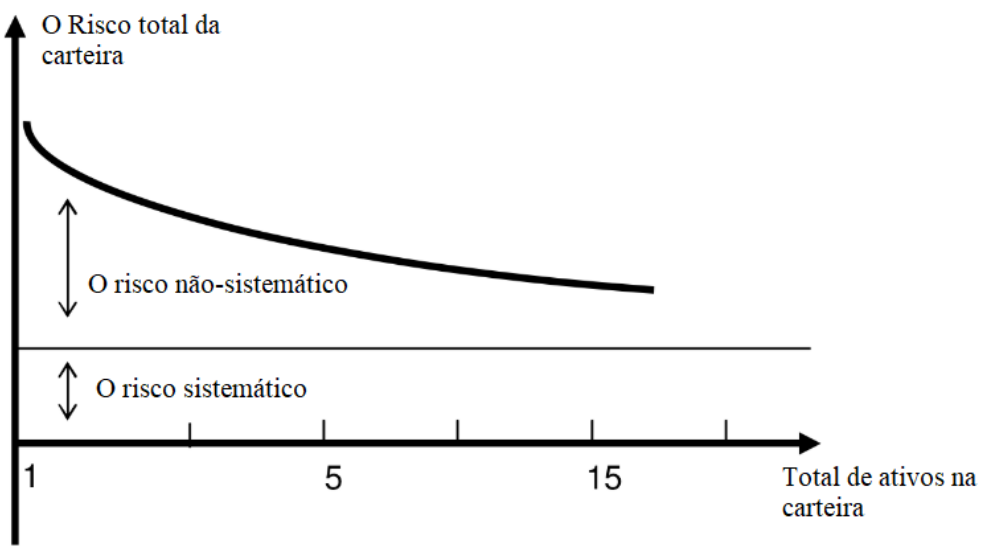

Fonte: Pro Educacional (2018).

\subsection{Diversificação}

Segundo o blog do BTG pactual (2017), "a diversificação de investimentos é uma técnica de diluição de risco e maximização de ganhos. Ela consiste em alocar recursos em diferentes aplicações financeiras, de modo que o desempenho negativo de uma não signifique perdas definitivas ao investidor".

Dado isso, podemos dizer que diversificar é você comprar ativos que variam com diferentes padrões. No caso do investimento em ações, a diversificação ocorre quando compramos diversas ações de diferentes setores da economia, a diversificação setorial. Ou quando compramos ações de diferentes lugares do mundo (diferentes bolsas), a diversificação geográfica. Pois um conjunto de ações de diferentes setores e/ou lugares possui correlações mais baixas do que um conjunto de ações do mesmo setor ou do mesmo lugar, ou seja, variam de 
diferentes formas. O risco de uma carteira é reduzido quando compramos ativos cujos preços descem e sobem de forma contrária.

\subsection{Aversão ao Risco}

A aversão ao risco é um conceito da psicologia que estuda o comportamento humano frente a um cenário de incerteza. Quando trazemos esse conceito para o campo das finanças comportamentais, é possível comparar o cenário de incerteza ao mundo dos investimentos.

"A aversão ao risco é o sentimento individual de cada investidor em relação ao risco de um investimento. É ele que faz com que o investidor abra mão de boas oportunidades de rentabilidade por temer o risco de perder parte de suas finanças aplicadas e, assim, sofrer um prejuízo." (Suno Research, 2019)

Segundo Damadoran (2008), as pessoas se comportam de maneiras diferentes diante dos riscos, e muitas vezes de modo irracional. Com isso, podemos dizer que os investidores pesquisados possuem diferentes formas de se comportar. Uns são mais arrojados - mais propensos a assumir riscos -, e outros são mais avessos aos riscos. 


\section{Coleta de Dados}

A coleta de dados foi feita da seguinte forma: todos os dados em relação a preços de ações das empresas escolhidas foram retirados do site Investing.com. As empresas escolhidas foram: JBS SA (JBSS3); Ambev SA (ABEV3); MRV Engenharia e Participações SA (MRVE3); Itaú Unibanco Holding SA (ITUB3); Petróleo Brasileiro SA (PETR3); TIM Participações SA (TIMP3); Fleury SA (FLRY3); Cogna Educação (COGN3); Lojas Renner SA (LREN3); Linx (LINX3); Walmart Inc (WMT); Yonghui Superstores Co Ltd (601933); ICA Gruppen AB (ICAA); Lojas Americanas SA (LAME3); Aeon Co., Ltd. (8267); Woolworths (WOW); Trent Ltd (TREN); Picknpay (PIKJ); Koninklijke Ahold Delhaize NV (AD); e President Chain Store Corp (2912). O preço das ações analisado foi o preço de fechamento do último dia do pregão de cada mês, de Janeiro de 2015 a Dezembro de 2019.

Primeiramente, as empresas foram analisadas separadamente quanto ao retorno esperado e seu desvio padrão, ou seja, risco. E com esses dados, foi possível calcular, posteriormente, a covariância e a correlação entre todos os ativos, o retorno esperado da carteira e o risco da carteira.

Quanto à montagem das carteiras, temos 3 carteiras, sendo uma com as ações das primeiras 10 empresas citadas acima, outra com as 10 seguintes, e uma terceira com todas as 20 ações. Vale ainda ressaltar que todas as ações tiveram o mesmo peso nas respectivas carteiras.

A primeira carteira é formada por ativos apenas negociados na bolsa brasileira (B3), e são empresas de diferentes setores e atividades-fim: JBS SA (Indústria de alimentos - Frigorífico); Ambev SA (Indústria de Bebidas); MRV engenharia e Participações (construtora); Itaú Unibanco Holding SA (Banco - Financeira); Petróleo Brasileiro SA (Petroquímica); TIM Participações SA (Telecomunicações); Fleury SA (Saúde); Cogna Educação (Educação); Lojas Renner SA (Varejo); e Linx (Tecnologia Software). Ou seja, esta carteira está sofrendo diversificação setorial.

A segunda carteira é formada por ações somente de empresas varejistas, porém negociadas em diferentes bolsas de valores: Walmart Inc (NYSE); Yonghui Superstores Co Ltd (Shangai); ICA Gruppen AB (Estocolmo); Lojas Americanas SA (B3); Aeon Co., Ltd. (Tokyo); Woolworths (Sydney); Trent Ltd (NSE); Picknpay (Joanesburgo); Koninklijke 
Ahold Delhaize NV (Amsterdã); e President Chain Store Corp (Taiwan). Ou seja, temos ações dos Estados Unidos, China, Suécia, Brasil, Japão, Austrália, Índia, África do Sul, Holanda e Taiwan. Dessa forma, estamos diversificando apenas geograficamente.

A terceira carteira, formada por todas as ações, possui o objetivo de mostrar que diversificar de ambas as formas é a maneira mais eficiente de se montar uma carteira quanto a risco e retorno.

Em relação à pesquisa junto a investidores, a coleta de dados foi feita através de um formulário do google forms. Este formulário foi colocado em grupos de Whatsapp de investimentos, pois são os investidores do mercado de ações brasileiro que estamos buscando entender.

\subsection{Metodologia do Estudo}

Para avaliarmos as carteiras em termos de eficiência em relação a risco/retorno, usamos o Índice de Sharpe. De acordo com HC Investimentos (2011), "o Índice de Sharpe, criado por William Sharpe (Nobel de Economia em 1990), é um indicador que permite avaliar a relação entre o retorno e o risco de um investimento. Ele mede qual é a relação entre o retorno excedente ao ativo livre de risco e a volatilidade."

\section{Figura 8: Fórmula do Índice de Sharpe}

$$
\text { IS = ( Ri -Rf ) / ( } \sigma \mathrm{i})
$$

Onde: IS= Índice de Sharpe; $\mathrm{Ri}=$ Retorno do Investimento; $\mathrm{Rf}=$ Retorno Livre de Risco; e $\sigma i=$ Risco do Investimento (volatilidade).

Fonte: HC Investimentos (2011).

Além disso, trouxemos as comparações entre as carteiras em relação à correlação e covariância dos seus ativos. Assim, será possível mostrar o impacto da diversificação.

Em relação ao formulário, foi feita uma pergunta filtro, na qual quem não fosse investidor de ações na bolsa brasileira não responderia o resto da entrevista. As perguntas foram colocadas com a finalidade de entender o porquê de os 
investidores brasileiros estarem evitando a compra de ações de bolsas estrangeiras e como eles se sentem sobre isso. $E$ qual o grau de desconforto em relação a certas situações que eles iriam se deparar, caso decidissem investir.

Por fim, vale ressaltar o conceito do Home Bias. Pois este cenário em que os investidores domésticos não compram ativos internacionais é o que caracteriza esse viés comportamental. Desta forma, podemos medir como o brasileiro se comporta quando está investindo. 


\section{Análise dos dados}

Neste capítulo serão apresentados os resultados das duas pesquisas realizadas. Primeiramente, a pesquisa documental, na qual pegamos dados já existentes e os analisamos a fim de analisar os efeitos das diferentes diversificações. E a segunda pesquisa, que é uma pesquisa de campo, em que buscamos entender melhor o comportamento do investidor.

\subsection{Teoria da Carteira, Covariância e Correlação}

Para realizar este estudo, usamos a teoria da carteira de ativos. Assim, conseguimos consolidar os retornos e riscos das ações que foram calculadas, previamente, de forma separada. Logo, identificando as covariância e correlações entre os ativos escolhidos para achar o risco da carteira. Dessa forma, será possível evidenciar o impacto da diversificação.

\subsubsection{Retorno e Risco dos Ativos}

Podemos iniciar a análise dos resultados deste estudo, relatando sobre o retorno esperado e o risco de cada ativo separadamente. Vale destacar que foi usada, para o cálculo do retorno, a média geométrica. Pois, por se tratar de uma análise longa - 60 períodos - e com diversas altas e baixas, a média geométrica nos dá um número mais justo. Já para o cálculo do risco, foi usado o desvio padrão.

A tabela adiante resume os resultados. 
Tabela 1: Retorno Esperado e Risco

\begin{tabular}{|l|r|r|l|l|r|}
\hline \multicolumn{5}{|c|}{ Carteira 3 } \\
\hline & Retorno & Risco & & \multicolumn{3}{c|}{ Carteira 2 } \\
\hline & $1,50 \%$ & $11,96 \%$ & WMT & $0,57 \%$ & $5,13 \%$ \\
\hline JBSS3 & $0,30 \%$ & $5,51 \%$ & 601933 & $0,90 \%$ & $10,09 \%$ \\
\hline ABEV3 & $2,46 \%$ & $10,24 \%$ & ICAA & $0,54 \%$ & $5,63 \%$ \\
\hline MRVE3 & $1,62 \%$ & $6,87 \%$ & LAME3 & $1,24 \%$ & $7,75 \%$ \\
\hline ITUB3 & $2,39 \%$ & $13,72 \%$ & AEON & $1,01 \%$ & $6,65 \%$ \\
\hline PETR3 & $0,61 \%$ & $8,07 \%$ & WOW & $0,22 \%$ & $4,28 \%$ \\
\hline TIMP3 & $2,79 \%$ & $9,27 \%$ & TREN & $2,20 \%$ & $8,82 \%$ \\
\hline FLRY3 & $2,7 \%$ & Risco \\
\hline COGN3 & $0,05 \%$ & $11,88 \%$ & PIKJ & $0,18 \%$ & $6,88 \%$ \\
\hline LREN3 & $2,67 \%$ & $7,66 \%$ & AD & $0,56 \%$ & $5,96 \%$ \\
\hline LINX3 & $1,46 \%$ & $10,98 \%$ & 2912 & $0,38 \%$ & $4,30 \%$ \\
\hline
\end{tabular}

Fonte: Elaboração própria (2020).

É possível perceber que os retornos esperados das ações brasileiras são maiores do que os "internacionais". Isso ocorre pelo fato do Brasil ser uma economia emergente. Se pegarmos a ação da Trent Ltd (TREN), podemos perceber que ela também possui um alto retorno esperado, pois essa empresa também está localizada numa economia emergente, no caso a Índia.

Em termos de risco, é notável também o maior risco das ações das empresas brasileiras. O Brasil é um país com certo grau de risco, quando analisamos pelo índice risco-país, por exemplo. O panorama político, mercadológico e sócio-geográfico brasileiro torna essas variações de preços das ações maiores e mais constantes do que em outros países mais estruturados e desenvolvidos, como Estados Unidos, Suécia, Japão, Austrália, entre outros. Portanto, tivemos resultados esperados.

\subsubsection{Retorno da Carteira}

Quanto ao retorno da carteira, usamos uma simples média aritmética, pois a amostra é pequena e todos os números são positivos, ou seja, não era necessário o usa da média geométrica. Além disso, vale indicar que todas as ações têm o mesmo peso em suas carteiras, logo não é preciso fazer uma média 
ponderada. E como os preços das ações foram calculados de forma mensal, essas taxas de retorno esperado são ao mês.

\section{Tabela 2: Retorno Esperado da Carteira}

\begin{tabular}{|l|r|l|r|}
\hline \multicolumn{4}{|c|}{ Carteira 3 } \\
\hline \multicolumn{2}{|c|}{ Carteira 1 } & \multicolumn{2}{c|}{ Carteira 2 } \\
\hline JBSS3 & $1,50 \%$ & WMT & $0,57 \%$ \\
\hline ABEV3 & $0,30 \%$ & 601933 & $0,90 \%$ \\
\hline MRVE3 & $2,46 \%$ & ICAA & $0,54 \%$ \\
\hline ITUB3 & $1,62 \%$ & LAME3 & $1,24 \%$ \\
\hline PETR3 & $2,39 \%$ & AEON & $1,01 \%$ \\
\hline TIMP3 & $0,61 \%$ & WOW & $0,22 \%$ \\
\hline FLRY3 & $2,79 \%$ & TREN & $2,20 \%$ \\
\hline COGN3 & $0,05 \%$ & PIKJ & $0,18 \%$ \\
\hline LREN3 & $2,67 \%$ & AD & $0,56 \%$ \\
\hline LINX3 & $1,46 \%$ & 2912 & $0,38 \%$ \\
\hline Total & $1,59 \%$ & Total & $0,78 \%$ \\
\hline Total Carteira 3 & $1,18 \%$ \\
\hline
\end{tabular}

Fonte: Elaboração própria (2020).

Dado o fato já mencionado no item 4.1.1 sobre o retorno esperado das ações negociadas na bolsa brasileira, podemos dizer que os resultados foram esperados. A Carteira 1 sendo a com maior retorno, a Carteira 2 o menor retorno, e a Carteira 3 sendo a média entre as duas, pois todas as ações possuem o mesmo peso.

\subsubsection{Covariância}

A covariância foi calculada através de uma média da multiplicação da variação do preço das ações menos o retorno esperado, de duas ações no mesmo período. Ou seja, primeiramente calculamos a variação do preço da ação menos o retorno esperado, para todas as ações e em todos períodos estudados. Depois, pegamos esses resultados, por período, de uma ação e multiplicamos pelos resultados de outra ação, no mesmo período. Por fim, fazemos a média, e assim, chegamos à covariância entre 2 ativos. 
Podemos dizer que a variação do preço menos o retorno esperado significa a distância da variação de um determinado período em relação ao que era esperado. E quando multiplicamos com o resultado de outra ação, achamos uma relação entre essas variações. Quanto menor for esta relação, maior é a diversificação se essas duas ações forem colocadas numa mesma carteira. Pois, significa que elas variam de forma mais antagônica, ou seja, quando uma sobe, a outra desce. Assim, há a diminuição do risco não sistemático.

$\mathrm{Na}$ tabela 3 adiante é apresentada a covariância entre as ações das três carteiras. Note que a Carteira 1 está no quadrante esquerdo superior, a $\underline{\text { Carteira } 2}$ no quadrante direito superior, e a Carteira 3 é formada pelos quatro quadrantes.

\section{Tabela 3: Tabela de Covariância}

\begin{tabular}{|c|c|c|c|c|c|c|c|c|c|}
\hline \multicolumn{10}{|c|}{ Carteira 3} \\
\hline \multicolumn{5}{|c|}{ Carteira 1} & \multicolumn{5}{|c|}{ Carteira2 } \\
\hline JBSS $3 \times$ ABEV 3 & JBSS3 X MRVE3 & JBSS3 X ITUB3 & JBSS3 X PETR3 & ABEV $3 \times$ MRVE 3 & WMT X 601933 & WMT X ICAA & WMT X LAME3 & WMT X AEON & 601933 X ICAA \\
\hline $0,13 \%$ & $0,06 \%$ & $0,02 \%$ & $-0,09 \%$ & $0,15 \%$ & $-0,01 \%$ & $0,04 \%$ & $-0,04 \%$ & $0,00 \%$ & $-0,02 \%$ \\
\hline ABEV3 X ITUB3 & ABEV $3 \times$ PETR3 & MRVE3 X ITUB3 & MRVE3 X PETR3 & ITUB3 X PETR3 & 601933 X LAME3 & 601933 X AEON & ICAA X LAME3 & ICAA X AEON & LAME3 X AEON \\
\hline $0,11 \%$ & $0,11 \%$ & $0,30 \%$ & $0,36 \%$ & $0,70 \%$ & $-0,01 \%$ & $0,00 \%$ & $0,05 \%$ & $0,00 \%$ & $-0,05 \%$ \\
\hline JBSS3 X TIMP3 & JBSS3 X FLRY3 & JBSS 3 X COGN3 & JBSS3 $X$ LREN3 & JBSS3 X LINX3 & WMT X WOW & WMT X TREN & WMT X PIKJ & WMT X AD & WMT X 2912 \\
\hline$-0,02 \%$ & $0,25 \%$ & $-0,01 \%$ & $0,15 \%$ & $-0,06 \%$ & $0,04 \%$ & $0,03 \%$ & $-0,03 \%$ & $0,04 \%$ & $0,04 \%$ \\
\hline ABEV 3 X TIMP3 & ABEV $3 X$ FLRY3 & ABEV $3 \times$ COGN3 & ABEV $3 \times$ LREN3 & ABEV3 X LINX3 & $601933 \times$ Wow & 601933 X TREN & 601933 X PIKJ & 601933 X AD & $601933 \times 2912$ \\
\hline $0,14 \%$ & $0,20 \%$ & $0,26 \%$ & $0,10 \%$ & $-0,10 \%$ & $-0,06 \%$ & $0,02 \%$ & $-0,03 \%$ & $-0,04 \%$ & $-0,04 \%$ \\
\hline MRVE3 X TIMP3 & MRVE3 X FLRY3 & MRVE3 X COGN3 & MRVE3 X LREN3 & MRVE3 X LINX3 & ICAA X WOW & ICAA X TREN & ICAA X PIKJ & ICAA X AD & ICAA X 2912 \\
\hline $0,37 \%$ & $0,29 \%$ & $0,58 \%$ & $0,35 \%$ & $0,23 \%$ & $0,06 \%$ & $0,04 \%$ & $-0,02 \%$ & $0,04 \%$ & $0,02 \%$ \\
\hline ITUB3 X TIMP3 & ITUB3 X FLRY3 & ITUB3 X COGN3 & ITUB3 X LREN3 & ITUB3 X LINX3 & LAME3 X WOW & LAME3 X TREN & LAME3 X PIKJ & LAME3 X AD & LAME3 X 2912 \\
\hline $0,27 \%$ & $0,26 \%$ & $0,33 \%$ & $0,30 \%$ & $0,16 \%$ & $0,01 \%$ & $0,07 \%$ & $0,06 \%$ & $0,01 \%$ & $-0,05 \%$ \\
\hline PETR3 X TIMP3 & PETR3 X FLRY3 & PETR3 X COGN3 & PETR3 X LREN3 & PETR3 X LINX3 & AEON X WOW & AEON X TREN & AEON X PIKJ & AEON X AD & AEON X 2912 \\
\hline $0,38 \%$ & $0,41 \%$ & $0,70 \%$ & $0,51 \%$ & $0,20 \%$ & $-0,01 \%$ & $-0,10 \%$ & $0,15 \%$ & $0,04 \%$ & $0,03 \%$ \\
\hline TIMP3 X FLRY3 & TIMP3 X COGN3 & TIMP3 X LREN3 & TIMP3 X LINX3 & FLRY3 X COGN3 & WOW X TREN & WOW X PIKJ & WOW X AD & WOW X 2912 & TREN X PIKJ \\
\hline $0,34 \%$ & $0,38 \%$ & $0,20 \%$ & $0,08 \%$ & $0,44 \%$ & $0,04 \%$ & $0,04 \%$ & $0,07 \%$ & $0,02 \%$ & $0,04 \%$ \\
\hline FLRY3 X LREN3 & FLRY3 X LINX3 & COGN3 X LREN3 & COGN3 X LINX3 & LREN3 X LINX3 & TREN X AD & TREN X 2912 & PIKJ X AD & PIKJ X 2912 & AD $\times 2912$ \\
\hline $0,20 \%$ & $0,00 \%$ & $0,32 \%$ & $0,09 \%$ & $0,30 \%$ & $0,12 \%$ & $-0,07 \%$ & $-0,01 \%$ & $-0,02 \%$ & $0,00 \%$ \\
\hline JBSS3 X WMT & JBSS3 X 601933 & JBSS3 X ICAA & JBSS3 $\times$ LAME3 & JBSS3 X AEON & JBSS3 $\times$ WOW & JBSS3 X TREN & JBSS3 X PIKJ & JBSS3 X AD & JBSS3 X 2912 \\
\hline $0,05 \%$ & $0,09 \%$ & $0,01 \%$ & $0,10 \%$ & $-0,05 \%$ & $0,12 \%$ & $0,04 \%$ & $0,05 \%$ & $0,08 \%$ & $-0,13 \%$ \\
\hline ABEV3 X WMT & ABEV3 X 601933 & ABEV $3 \times$ ICAA & ABEV $3 \times$ LAME3 & ABEV 3 X AEON & ABEV3 X WOW & ABEV $3 \times$ TREN & ABEV3 X PIKJ & ABEV3 X AD & ABEV $3 \times 2912$ \\
\hline $0,03 \%$ & $0,01 \%$ & $-0,01 \%$ & $0,13 \%$ & $0,00 \%$ & $-0,02 \%$ & $0,02 \%$ & $0,05 \%$ & $0,03 \%$ & $-0,04 \%$ \\
\hline MRVE3 X WMT & MRVE3 X 601939 & MRVE3 X ICAA & MRVE3 X LAME3 & MRVE3 X AEON & MRVE3 X WOW & MRVE3 X TREN & MRVE3 X PIKJ & MRVE3 X AD & MRVE3 X 2912 \\
\hline$-0,01 \%$ & $0,17 \%$ & $0,01 \%$ & $0,35 \%$ & $-0,23 \%$ & $0,01 \%$ & $0,16 \%$ & $0,06 \%$ & $0,01 \%$ & $0,00 \%$ \\
\hline ITUB3 X WMT & ITUB3 X 601933 & ITUB3 X ICAA & ITUB3 X LAME3 & ITUB3 X AEON & ITUB3 X WOW & ITUB3 X TREN & ITUB3 X PIKJ & ITUB3 X AD & ITUB3 X 2912 \\
\hline $0,01 \%$ & $0,08 \%$ & $0,04 \%$ & $0,35 \%$ & $-0,02 \%$ & $-0,01 \%$ & $0,09 \%$ & $0,11 \%$ & $-0,01 \%$ & $-0,08 \%$ \\
\hline PETR3 X WMT & PETR3 X 601933 & PETR3 X ICAA & PETR3 X LAME3 & PETR3 X AEON & PETR3 X WOW & PETR3 X TREN & PETR3 X PIKJ & PETR3 X AD & PETR3 $\times 2912$ \\
\hline$-0,04 \%$ & $0,20 \%$ & $0,07 \%$ & $0,43 \%$ & $0,14 \%$ & $-0,05 \%$ & $-0,16 \%$ & $0,35 \%$ & $-0,09 \%$ & $-0,08 \%$ \\
\hline TIMP3 X WMT & TIMP3 X 601933 & TIMP3 X ICAA & TIMP3 X LAME3 & TIMP3 X AEON & TIMP3 X WOW & TIMP3 X TREN & TIMP3 X PIKJ & TIMP3 X AD & TIMP3 X 2912 \\
\hline$-0,01 \%$ & $0,08 \%$ & $0,00 \%$ & $0,33 \%$ & $-0,03 \%$ & $0,08 \%$ & $0,05 \%$ & $0,15 \%$ & $0,02 \%$ & $0,01 \%$ \\
\hline FLRY3 X WMT & FLRY3 X 601933 & FLRY3 X ICAA & FLRY3 X LAME3 & FLRY3 X AEON & FLRY3 X WOW & FLRY3 $X$ TREN & FLRY3 X PIKJ & FLRY3 X AD & FLRY3 X 2912 \\
\hline $0,06 \%$ & $0,15 \%$ & $0,02 \%$ & $0,30 \%$ & $0,01 \%$ & $0,04 \%$ & $0,11 \%$ & $0,14 \%$ & $0,05 \%$ & $-0,05 \%$ \\
\hline COGN3 X WMT & COGN3 X 601933 & COGN3 X ICAA & COGN3 X LAME3 & COGN3 X AEON & COGN3 X WOW & COGN3 X TREN & COGN3 X PIKJ & COGN3 X AD & COGN3 X 2912 \\
\hline$-0,05 \%$ & $0,11 \%$ & $-0,01 \%$ & $0,38 \%$ & $-0,01 \%$ & $-0,09 \%$ & $-0,01 \%$ & $0,15 \%$ & $-0,08 \%$ & $-0,01 \%$ \\
\hline LREN3 X WMT & LREN3 X 601933 & LREN3 X ICAA & LREN3 X LAME3 & LREN3 X AEON & LREN3 X WOW & LREN3 X TREN & LREN3 X PIKJ & LREN3 X AD & LREN3 X 2912 \\
\hline $0,04 \%$ & $0,12 \%$ & $0,07 \%$ & $0,38 \%$ & $-0,08 \%$ & $0,02 \%$ & $-0,02 \%$ & $0,01 \%$ & $0,02 \%$ & $-0,02 \%$ \\
\hline LINX3 X WMT & LINX3 X 601933 & LINX3 X ICAA & LINX3 X LAME3 & LINX3 X AEON & LINX3 X WOW & LINX3 $X$ TREN & LINX3 X PIKJ & LINX3 X AD & LINX3 X 2912 \\
\hline $0,06 \%$ & $0,15 \%$ & $0,02 \%$ & $0,30 \%$ & $0,01 \%$ & $0,04 \%$ & $0,11 \%$ & $0,14 \%$ & $0,05 \%$ & $-0,05 \%$ \\
\hline
\end{tabular}

Fonte: Elaboração própria (2020). 
Os resultados colocados em azul são todas as covariâncias acima de $0,10 \%$, e os resultados em laranja são todos os negativos. Os resultados negativos ocorrem, quando em alguns determinados períodos, o preço de uma ação sobe enquanto o da ação que está sendo relacionada desce. Logo, multiplicando um número positivo com outro negativo, temos um negativo. Ou seja, se colocarmos essa ações numa carteira, menor vai ser o risco da carteira perder valor, dado que quando o valor de um ativo desce, o do outro sobe.

Podemos perceber que a Carteira 2, a qual utilizamos a diversificação geofráfica, diversifica bem mais o risco do que a Carteira 1, a qual usamos diversificação setorial. Portanto, os preços das ações da Carteira 2 variam de forma mais contrária do que os preços das ações da Carteira 1.

Ao olharmos para a Carteira 3, vale evidenciar a covariância da Lojas Americanas SA com as ações da Carteira 1. Comparando com as outras covariâncias entre as ações da carteira 1 e 2, percebemos que a diversificação que ocorre comprando ações da mesma bolsa é muito menor do que comprando de bolsas diferentes. Ainda é válido ressaltar que as ações da carteira 2 são todas ações de empresas do mesmo setor.

\subsubsection{Coeficiente de Correlação}

A correlação é a covariância dividida pela multiplicação do desvio padrão das duas ações, e pode variar de -1 a +1 . Quanto mais perto de +1 , mais parecida é a variação dos preços dos ativos em questão - ou seja, possuem uma relação positiva -, enquanto que quanto mais perto de -1 for o coeficiente, mais antagônica é essa variação - ou seja, possuem uma relação negativa. 
Tabela 4: Tabela de Correlação

\begin{tabular}{|c|c|c|c|c|c|c|c|c|c|}
\hline \multicolumn{10}{|c|}{ Carteira 3} \\
\hline \multicolumn{5}{|c|}{ Carteira 1} & \multicolumn{5}{|c|}{ Carteira 2} \\
\hline JBSS $3 \times$ ABEV 3 & JBSS3 X MRVE3 & JBSS3 X ITUB3 & JBSS 3 X PETR3 & ABEV $3 \times$ MRVE3 & WMT X 601933 & WMT X ICAA & WMT X LAME3 & WMT X AEON & 601933 X ICAA \\
\hline 0,203 & 0,048 & 0,029 & $-0,056$ & 0,257 & $-0,023$ & 0,135 & $-0,111$ & 0,013 & $-0,028$ \\
\hline ABEV3 X ITUB3 & ABEV 3 X PETR3 & MRVE3 X ITUB3 & MRVE3 X PETR3 & ITUB3 X PETR3 & 601933 X LAME3 & $601933 \times$ AEON & ICAA X LAME 3 & ICAA X AEON & LAME3 X AEON \\
\hline 0,300 & 0,143 & 0,426 & 0,256 & 0,737 & $-0,010$ & $-0,006$ & 0,118 & 0,004 & $-0,095$ \\
\hline JBSS3 X TIMP3 & JBSS3 X FLRY3 & JBSS $3 \times$ COGN3 & JBSS3 X LREN3 & JBSS3 X LINX3 & WMT X WOW & WMT X TREN & WMT X PIKJ & WMT X AD & WMT X 2912 \\
\hline$-0,016$ & 0,224 & $-0,009$ & 0,166 & $-0,043$ & 0,197 & 0,065 & $-0,076$ & 0,136 & 0,172 \\
\hline ABEV $3 \times$ TIMP3 & ABEV 3 X FLRY3 & ABEV $3 \times$ COGN3 & ABEV $3 \times$ LREN 3 & ABEV 3 X LINX3 & 601933 x WOW & 601933 X TREN & 601933 X PIKJ & $601933 \times A D$ & $601933 \times 2912$ \\
\hline 0,312 & 0,383 & 0,403 & 0,235 & $-0,164$ & $-0,133$ & 0,026 & $-0,048$ & $-0,067$ & $-0,103$ \\
\hline MRVES X TIMP3 & MRVE3 X FLRY3 & MRVE3 X COGN3 & MRVE3 $X$ LREN3 & MRVE3 X LINX3 & ICAAX WOW & ICAA X TREN & ICAA X PIKJ & ICAA X AD & ICAA X 2912 \\
\hline 0,445 & 0,301 & 0,473 & 0,441 & 0,203 & 0,243 & 0,082 & $-0,064$ & 0,125 & 0,098 \\
\hline ITUB3 X TIMP3 & ITUB3 X FLRY3 & ITUB3 X COGN3 & ITUB3 X LREN3 & ITUB3 X LINX3 & LAME3 $X$ WOW & LAME3 $X$ TREN & LAME3 X PIKJ & LAME3 $X$ AD & LAME3 X 2912 \\
\hline 0,485 & 0,404 & 0,409 & 0,577 & 0,208 & 0,036 & 0,100 & 0,103 & 0,023 & $-0,153$ \\
\hline PETR3 X TIMP3 & PETR3 X FLRY3 & PETR3 X COGN3 & PETR3 X LREN3 & PETR3 X LINX3 & AEON X WOW & AEON X TREN & AEON X PIKJ & AEON X AD & AEON X 2912 \\
\hline 0,343 & 0,322 & 0,429 & 0,485 & 0,132 & $-0,048$ & $-0,163$ & 0,339 & 0,095 & 0,098 \\
\hline TIMP3 X FLRY3 & TIMP3 X COGN3 & TIMP3 X LREN3 & TIMP3 X LINX3 & FLRY3 X COGN3 & WOW X TREN & WOW X PIKJ & WOW $\times A D$ & Wow X 2912 & TREN X PIKJ \\
\hline 0,450 & 0,397 & 0,321 & 0,087 & 0,395 & 0,093 & 0,142 & 0,286 & 0,108 & 0,067 \\
\hline FLRY3 X LREN3 & FLRY3 X LINX3 & COGN3 X LREN3 & COGN3 X LINX3 & LREN3 X LINX3 & TREN X AD & TREN X 2912 & PIKJ X AD & PIKJ X 2912 & $A D \times 2912$ \\
\hline 0,281 & 0,003 & 0,354 & 0,067 & 0,356 & 0,235 & $-0,185$ & $-0,023$ & $-0,069$ & $-0,001$ \\
\hline JBSS3 X WMT & JBSS3 X 601933 & JBSS $3 \times$ ICAA & JBSS $3 \times$ LAME3 & JBSS $3 \times$ AEON & JBSS3 X WOW & JBSS $3 \times$ TREN & JBSS3 X PIKJ & JBSS $3 \times A D$ & JBSS3 $\times 2912$ \\
\hline 0,089 & 0,071 & 0,008 & 0,112 & $-0,068$ & 0,243 & 0,042 & 0,065 & 0,116 & $-0,262$ \\
\hline ABEV3 X WMT & ABEV $3 \times 601933$ & ABEV $3 \times$ ICAA & ABEV $3 \times$ LAME3 & ABEV $3 \times$ AEON & ABEV $3 \times$ WOW & ABEV3 X TREN & ABEV3 X PIKJ & $A B E V 3 \times A D$ & ABEV $3 \times 2912$ \\
\hline 0,121 & 0,024 & $-0,027$ & 0,310 & 0,004 & $-0,074$ & 0,034 & 0,137 & 0,078 & $-0,170$ \\
\hline MRVE3 X WMT & MRVE3 X 601933 & MRVE3 X ICAA & MRVE3 X LAME3 & MRVES X AEON & MRVE3 X WOW & MRVE3 X TREN & MRVE3 X PIKJ & MRVE3 X AD & MRVE3 X 2912 \\
\hline$-0,015$ & 0,161 & 0,021 & 0,440 & $-0,336$ & 0,025 & 0,179 & 0,081 & 0,022 & 0,011 \\
\hline ITUB3 X WMT & ITUB3 X 601933 & ITUB3 X ICAA & ITUB3 X LAME3 & ITUB3 X AEON & ITUB3 X WOW & ITUB3 X TREN & ITUB3 X PIKJ & ITUB3 X AD & ITUB3 X 2912 \\
\hline 0,027 & 0,116 & 0,112 & 0,661 & $-0,042$ & $-0,021$ & 0,150 & 0,230 & $-0,016$ & $-0,261$ \\
\hline PETR3 X WMT & PETR3 X 601933 & PETR3 X ICAA & PETR3 X LAME3 & PETR3 X AEON & PETR3 X WOW & PETR3 X TREN & PETR3 X PIKJ & PETR3 X AD & PETR3 X 2912 \\
\hline$-0,061$ & 0,142 & 0,093 & 0,406 & 0,158 & $-0,083$ & $-0,132$ & 0,373 & $-0,109$ & $-0,138$ \\
\hline TIMP3 X WMT & TIMP3 X 601933 & TIMP3 X ICAA & TIMP3 X LAME3 & TIMP3 X AEON & TIMP3 X WOW & TIMP3 X TREN & TIMP3 X PIKJ & TIMP3 X AD & TIMP3 X 2912 \\
\hline$-0,029$ & 0,099 & $-0,008$ & 0,528 & $-0,063$ & 0,230 & 0,077 & 0,272 & 0,035 & 0,025 \\
\hline FLRY3 X WMT & FLRY3 X 601933 & FLRY3 X ICAA & FLRY3 X LAME3 & FLRY3 X AEON & FLRY3 X WOW & FLRY3 X TREN & FLRY3 X PIKJ & FLRY3 X AD & FLRY3 X 2912 \\
\hline 0,124 & 0,160 & 0,034 & 0,424 & 0,014 & 0,098 & 0,136 & 0,213 & 0,083 & $-0,119$ \\
\hline COGN3 X WMT & COGN3 X 601933 & COGN3 X ICAA & COGN3 X LAME3 & COGN3 X AEON & COGN3 $X$ WOW & COGN3 X TREN & COGN3 X PIKJ & COGN3 X AD & COGN3 X 2912 \\
\hline$-0,078$ & 0,088 & $-0,013$ & 0,413 & $-0,011$ & $-0,181$ & $-0,009$ & 0,188 & $-0,115$ & $-0,015$ \\
\hline LREN3 X WMT & LREN3 X 601933 & LREN3 X ICAA & LREN3 X LAME3 & LREN $3 \times$ AEON & LREN3 X WOW & LREN3 X TREN & LREN3 X PIKJ & LREN3 X AD & LREN3 $\times 2912$ \\
\hline 0,092 & 0,160 & 0,172 & 0,634 & $-0,165$ & 0,076 & $-0,030$ & 0,012 & 0,053 & $-0,053$ \\
\hline LINX3 X WMT & LINX3 X 601933 & LINX3 X ICAA & LINX3 X LAME3 & LINX3 X AEON & LINX3 X WOW & LINX3 X TREN & LINX3 X PIKJ & LINX3 X AD & LINX3 X 2912 \\
\hline 0,105 & 0,135 & 0,028 & 0,358 & 0,012 & 0,082 & 0,115 & 0,180 & 0,070 & $-0,100$ \\
\hline
\end{tabular}

\section{Fonte: Elaboração própria (2020).}

Os resultados colocados em azul são todas as correlações acima de 0,20, e os resultados em laranja são todos os negativos.

Os resultados foram parecidos com os da covariância, obviamente até por conta do cálculo, sendo o impacto da diversificação geográfica maior do que a setorial. A Carteira 2 possui coeficientes de correlação menores, ou seja, é mais diversificada que a Carteira 1.

Além disso, novamente, chama a atenção na Carteira 3 as Lojas Americanas SA (LAME3). Os coeficientes de correlação das Lojas Americanas com as ações da Carteira 1 são os maiores quando cruzamos as ações das Carteiras 1 e 2. 
Entretanto, podemos notar alguns diferentes resultados, como as correlações entre a Yonghui Superstores Co Ltd (601933) e as ações da Carteira 1, que ficaram abaixo do esperado. Nas covariâncias, estas mesmas relações foram maiores. Isto ocorre, pois o desvio padrão da empresa chinesa é alto comparado com as outras ações da Carteira 2. Logo, quando dividimos, chegamos a coeficientes mais baixos.

Ademais, foram consideradas relevantes as correlações acima de 0,20, mas as covariâncias tiveram uma restrição menor $(0,10 \%)$.

\subsubsection{Risco das Carteiras}

O risco das carteiras foi calulado usando a fórmula abaixo (Figura 9) com a covariância, mas também poderia ter sido usada a correlação para calcular (Figura 10), daria o mesmo resultado, depois de ajeitar a fórmula. Dado que a covariância é a correlação vezes os desvios padrões das ações relacionadas.

Figura 9: Fórmula do Risco da Carteira com 3 ativos

$$
\sigma_{p}=\sqrt{\begin{array}{l}
\left(w_{A}^{2} \times \sigma_{A}^{2}\right)+\left(w_{B}^{2} \times \sigma_{B}^{2}\right)+\left(w_{C}^{2} \times \sigma_{C}^{2}\right)+ \\
+2 \times w_{A} \times w_{B} \times C O V_{A, B}+ \\
+2 \times w_{A} \times w_{C} \times C O V_{A, C}+ \\
+2 \times w_{B} \times w_{C} \times C O V_{B, C}
\end{array}}
$$

Onde:

- W é o peso das ações na carteira. Como o cálculo considerou que todas as ações tinham o mesmo peso, $W=0,1$ nas Carteiras 1 e 2 (10 ativos), e $\mathrm{W}=\mathbf{0 , 0 5}$ na Carteira 3 (20 ativos); e

- $\sigma$ é o desvio padrão dos ativos.

Fonte: Top Invest - Risco da Carteira. 
Figura 10: Fórmula com Coeficiente de Correlação (2 ativos)

$$
\begin{aligned}
& \sigma_{\text {Carteira }}=\sqrt{\left(W_{A}^{2} \cdot \sigma_{A}^{2}\right)+\left(W_{B}^{2} \cdot \sigma_{B}^{2}\right)+2 \cdot\left(W_{A} \cdot W_{B} \cdot \rho_{A B} \cdot \sigma_{A} \cdot \sigma_{B}\right)} \\
& \text { Onde: } \\
& \sigma=\text { Desvio Padrầo } \\
& \rho=\text { Correlação entre os dois ativos } \\
& W=\text { Peso (\%) de cada ativo na carteira }
\end{aligned}
$$

Fonte: Trader Gráfico - Teoria de Carteiras parte 2

Porém, foram usados mais ativos: Carteira $1=10$ ativos; Carteira $2=10$ ativos; Carteira $3=20$ ativos. Mas respeitando a lógica da fórmula.

\section{Tabela 5: Risco das Carteiras}

\begin{tabular}{|l|l|}
\hline \multicolumn{2}{|c|}{ Risco da Carteira } \\
\hline Carteira 1 & $5,54 \%$ \\
\hline Carteira 2 & $2,38 \%$ \\
\hline Carteira 3 & $3,46 \%$ \\
\hline
\end{tabular}

Fonte: Elaboração própria (2020).

Podemos dizer que os resultados dos riscos das carteiras foram os esperados, pois os resultados da covariância e da correlação na Carteira 2 foram os mais baixos, enquanto os da Carteira 1 foram os mais altos, ou seja, a Carteira 2 diminuiu mais o risco não sitemático do que a Carteira 1. Além disso, as ações da Carteira 1 possuíram, de modo geral, maiores desvios-padrões do que as ações da Carteira 2.

\subsection{6. Índice de Sharpe}

Para calcular o Índice de Sharpe, colocamos o retorno esperado de forma anualizada - ou seja, [(retorno esperado/100 + 1) $\left.{ }^{\mathbf{1 2}}-1\right]$ x 100. Como já dito anteriormente, usamos para o retorno sem risco a Taxa Selic do final do ano de 
2019, ou seja, 4,5\%. O Índice de Sharpe serve para calcular a eficiência da carteira em termos de risco e retorno.

Tabela 6: Índice de Sharpe

\begin{tabular}{|l|l|}
\hline \multicolumn{2}{|c|}{ Índice de Sharpe } \\
\hline Carteira 1 & 2,939 \\
\hline Carteira 2 & 2,219 \\
\hline Carteira 3 & 3,084 \\
\hline
\end{tabular}

Fonte: Elaboração própria (2020).

O resultados mostram a Carteira 3 , na qual há diversificação geográfica e setorial, como sendo a mais eficiente. A Carteira 1 como a segunda mais eficiente, por conta do seu maior retorno esperado em relação à Carteira 2, que mesmo com o menor risco, ficou atrás pelo seu baixo retorno.

\subsection{Pesquisa de Campo}

Dado tudo o que foi mostrado até agora, buscaram-se investidores da B3 para entendê-los melhor. O objetivo foi compreender por que não procuram diversificar seus investimentos geograficamente, tendo em vista que a diversificação se comprovou algo efetivamente positivo.

Podemos dizer que essa pesquisa é um complemento para as evidências empíricas. Depois de entender a parte numérica, desejou-se compreender a parte comportamental do problema ocasionado pelo Home Bias.

\subsubsection{Aceitação de risco $\times$ Vontade de Investir em Bolsas estrangeiras}

Perguntamos aos investidores qual percentagem dos seus investimentos estão em ações, a fim de classificá-los em termos de aversão a risco. Como ações são consideradas investimentos de risco, podemos dizer que os investidores com $75 \%$ a $100 \%$ de ações em suas carteiras são maiores tomadores de risco, 
enquanto os com $0 \%$ a $25 \%$ são mais avessos ao risco. Então, cruzaram-se esses dados com os dados da pergunta sobre se havia vontade de investir em bolsas estrangeiras. Foram obtidos os seguintes resultados:

Gráfico 3: Vontade de Investir x Aversão a Risco (\%)

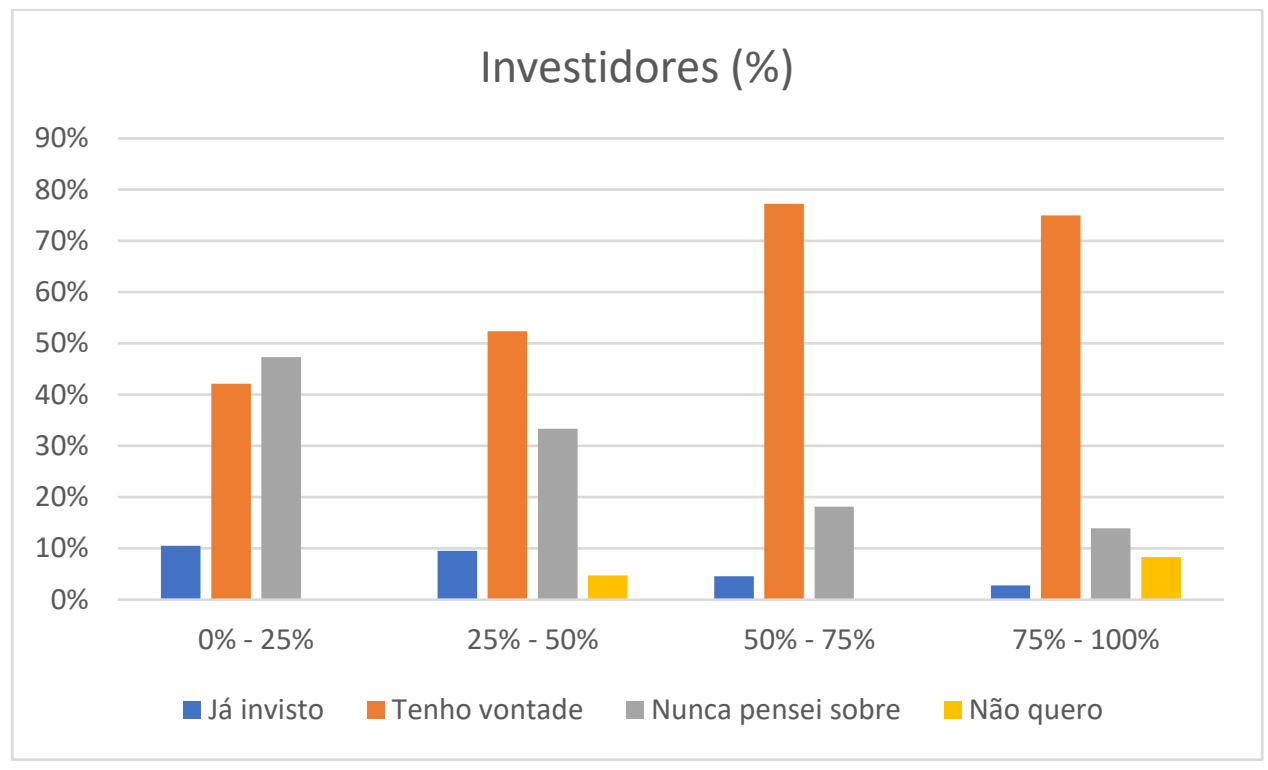

Fonte: Elaboração própria (2020).

\section{Gráfico 4: Vontade de Investir x Aversão a Risco}

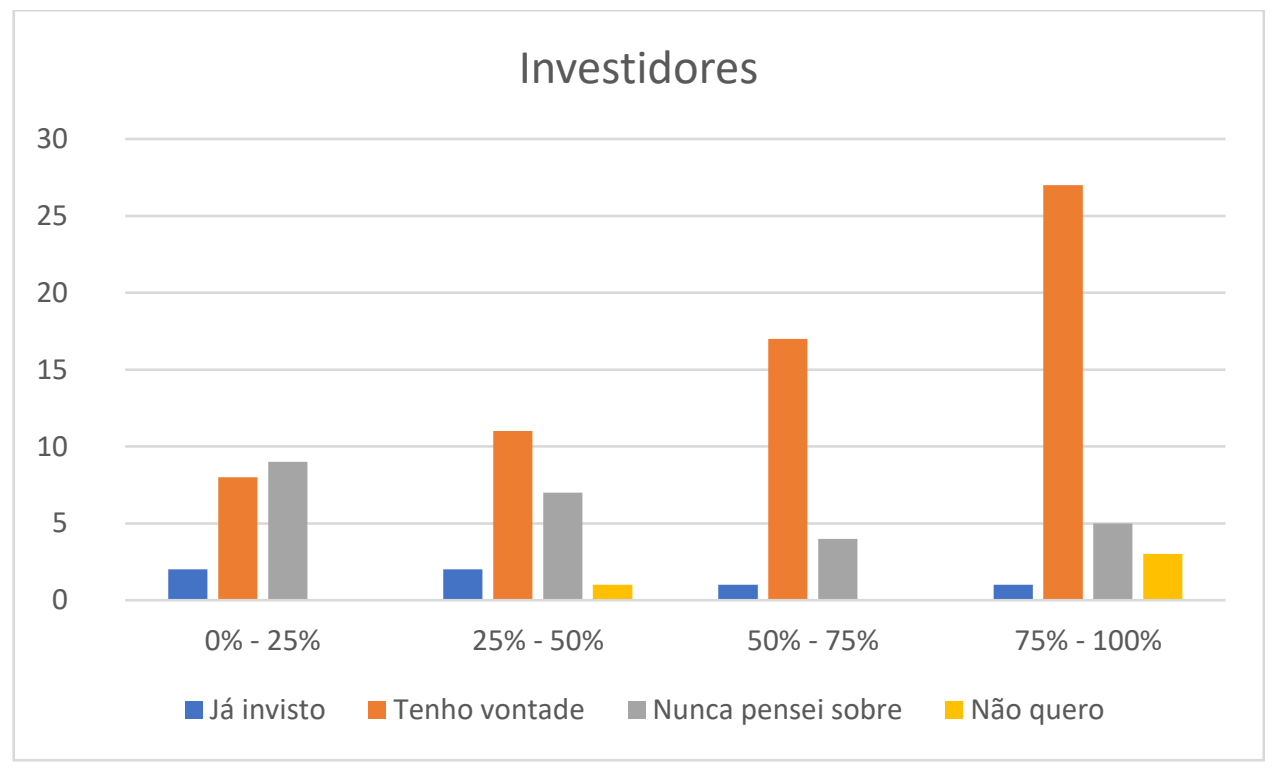

Fonte: Elaboração própria (2020). 
O que chama a atenção no gráfico 4 é o número de pessoas que não investem em bolsas do exterior, porém possuem a vontade de investir: 63 dos 98 entrevistados. Outro número que chamou a atenção é o de pessoas que nunca pensaram sobre o assunto, 25 dos 98 entrevistados, quando se esperava um número menos significativo. Também temos um baixo número de pessoas que já investem em ações de bolsas estrangeiras e de pessoas que não querem investir, dentro do esperado.

Analisando o gráfico 3, podemos evidenciar algumas relações entre a aceitação do risco e a vontade de investir em bolsas estrangeiras. Nesse gráfico, separamos os investidores em grupos de acordo com suas convicções em relação ao risco, e dividimos cada valor encontrado no gráfico 4 pelo o total de cada grupo. Assim, obtendo as porcentagens em relação à intenção dos investidores de comprar ações de outras bolsas, dentro de cada grupo.

Logo, vemos que a afinidade do investidor com o risco traz um maior desejo de diversificar geograficamente. Mais de $70 \%$ das pessoas que possuem entre $50 \%$ a $100 \%$ de seus investimentos em ações pensam em investir no exterior posteriomente. Nessa mesma linha de raciocínio, vemos que quanto maior é a aversão ao risco, maior é a porcentagem de pessoas que nunca cogitaram investir em ações no exterior.

Portanto, apesar da maior porcentagem de pessoas que já aplicam em bolsas estrangeiras ser no grupo de maior aversão ao risco, podemos dizer que quanto mais propenso a tomar risco é o investidor, maior é a vontade de investir em bolsas do exterior. Acredita-se que o fato do grupo mais avesso ao risco ter mais investidores que se aventuram no exterior se dá pelo motivo dos mesmos terem buscado justamente diminuir seus riscos, diversificando geograficamente. De qualquer forma, em todos os grupos, o percentual de pessoas que investem em bolsas estrangeiras é bem reduzido.

\subsubsection{Qual o motivo?}

Neste item, falaremos sobre os investidores que não querem investir em bolsas estrangeiras e os que nunca pensaram sobre. Procuramos saber por qual 
motivo essas pessoas não querem procurar este tipo de investimento. E obtivemos 26 repostas.

Os resultados foram (em ordem decrescente de repetição): falta de conhecimento, complexidade (impostos e dificuldades), medo, pouca informação, formas de acompanhar, otimismo no mercado interno (prêmio de risco e juros), começando a investir, nunca pensei, recessão americana e "nunca pensei sobre, mas agora que você falou, é boa ideia".

Destes resultados, podemos concluir que existe uma falta de informação para o investidor brasileiro sobre o assunto. Isso porque a pesquisa foi feita apenas com pessoas que investem em ações, ou seja, têm certa noção de finanças. Neste sentido, os gestores de carteiras poderiam ser mais instruídos para oferecer outras opções de investimento, até não buscando um lucro para sua empresa e para si, mas sim a satisfação do seu cliente. Com esses resultados, pressupõe-se que a educação financeira do brasileiro é relativamente fraca de uma forma geral.

Além disso, a visão do brasileiro quando falamos em investir no mercado financeiro externo é estreita para os Estados Unidos. Várias das respostas foram justificadas comparando a economia brasileira com a americana.

\subsubsection{Qual você acha que é ou pode ser a maior dificuldade em investir em bolsas estrangeiras?}

Neste item, perguntamos aos investidores que já investem ou que têm vontade de comprar ações em bolsas de outros países, qual é, ou qual eles pensam ser, a maior dificuldade em se investir em bolsas estrangeiras. $E$ obtivemos 59 respostas.

Novamente, deparamo-nos com a falta de informação e com as poucas ferramentas para acompanhar o mercado. Porém, o resultado que mais apareceu foi a burocracia - abrir conta, taxar imposto de renda. Além disso, o resultado foi bem dentro do esperado, pois conseguimos respostas relativas a todos os fatores que levavam as pessoas a não diversificar geograficamente, citados no item 1.1 (contextualização). Antes mesmo de perguntarmos sobre estes. 
No caso, as respostas foram: a falta de feeling do mercado por não morar e nem trabalhar nele (importância de estar próximo à empresa); fuso horário, falta de conhecimento do cenário macroeconômico, medo do desconhecido (diferenças culturais); língua (dificuldade com as línguas estrangeiras); conhecer muito bem a empresa e seus gestores (importância de conhecer o produto ou serviço que a empresa oferece); além da burocracia, que foi a mais mencionada.

Ademais, tivemos algumas respostas falando sobre o câmbio, nas quais novamente evidenciamos investidores brasileiros pegando os Estados Unidos como referência e citando o fato do dólar estar alto. Ainda vale ressaltar que obtivemos algumas respostas sobre o fato de não ter conhecimento de corretoras em outros países, confiáveis e com baixas taxas.

\subsubsection{Grau de importância das razões que levam os investidores a evitar a compra de ações de bolsas estrangeiras}

Após perguntarmos quais eram, seriam ou poderiam ser as maiores dificuldades de se investir no exterior, procuramos entender como os investidores brasileiros se sentiam em relação às questões das diferenças culturais, das diferenças linguísticas e burocráticas. E, aos graus de importância que os mesmos davam ao fato de usar/conhecer o produto ou serviço que a empresa oferece e estar próximo à empresa (ter algum conhecido que trabalha nela, morar perto, maior poder de fiscalização) na hora de comprar uma ação. Obtivemos 69 respostas.

\subsubsection{Diferenças Culturais}

Pergunta: Diferenças culturais entre os países? Sendo 5 uma grande dificuldade, e 0 nenhuma dificuldade. 


\section{Gráfico 5: Importância das Diferenças Culturais ao Investir}



Fonte: Elaboração própria (2020).

O resultado foi que as diferenças culturais são pouco relevantes na hora de comprar uma ação. Dado que 46 dos 69 votos foram de 0 a 2, e 23 votaram de 3 a 5 . A maioria dos investidores não atribui hábitos diferentes de consumo, horário de pregão, entre outras diferenças, como uma dificuldade na hora da compra de uma ação no exterior.

O resultado foi inesperado. A razão talvez seja por conta da questão da ligação do povo brasileiro com a cultura americana, e essa falsa crença de que quando falamos em investir na bolsa no exterior, estivermos falando em investir somente na bolsa americana.

\subsubsection{Diferenças Linguísticas}

Pergunta: Língua? Ex.: Relatórios da empresa em outra língua. Relacionamento com a corretora em outra língua. Sendo 5 grande dificuldade, 0 pouca dificuldade. 


\section{Gráfico 6: Importância das Diferenças Línguísticas ao Investir}

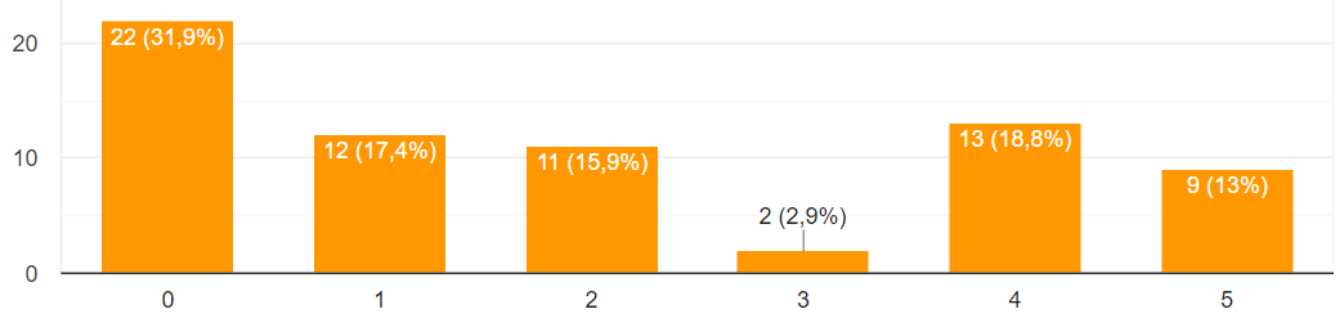

Fonte: Elaboração própria (2020).

A maioria dos investidores pesquisados acha que a barreira linguística não é uma grande dificuldade na hora de investir, 45 dos 69 entrevistados optaram pelas opções de 0 a 2. Acredita-se que realmente não seja uma grande dificuldade a abertura de conta e o relacionamento com a corretora, pois a língua inglesa é uma língua mundial, quem a domina não terá problemas para operar em qualquer lugar do mundo. Porém, para análise de relatórios de empresas, há uma maior dificuldade.

Por esses motivos, o resultado foi esperado. Por conta do filtro que fizemos no início, no qual só responderam às perguntas as pessoas que possuem ações na bolsa B3 - investidores de ações geralmente são pessoas mais instruídas. Se fossemos perguntar para a população brasileira, acredito que essa dificuldade teria um resultado mais relevante. Pois, segundo o Money Times (2019), apenas 5\% dos brasileiros falam inglês, e 1 \% são fluentes na língua.

\subsubsection{Importância de usar/conhecer o serviço ou produto}

Pergunta: O quão importante para você é usar/conhecer o serviço ou produto das empresas das quais você compra a ação? Sendo 5 muito importante, 0 pouco importante. 


\section{Gráfico 7: Importância de usar/conhecer o serviço ou produto ao Investir.}

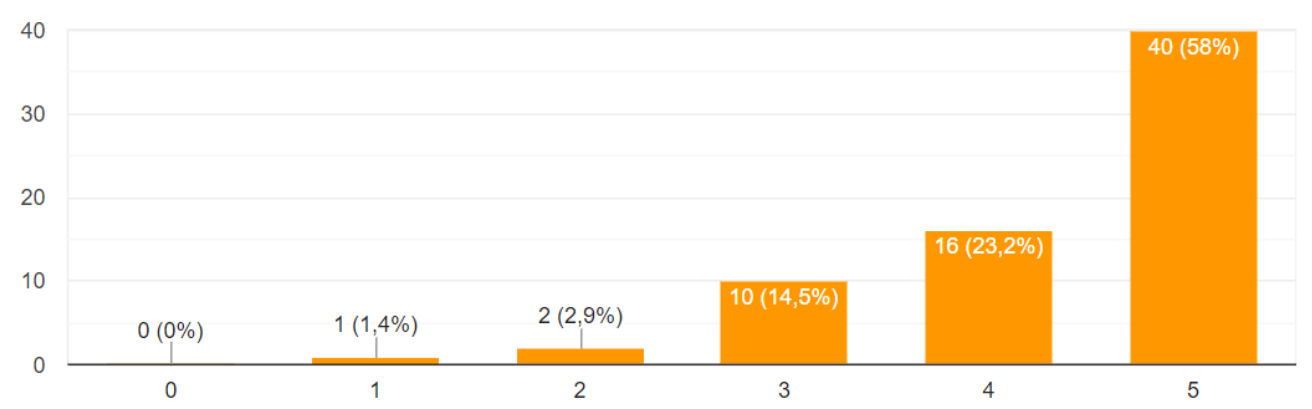

Fonte: Elaboração própria (2020).

Os investidores brasileiros acharam de grande importância usar ou conhecer o produto ou serviço das empresas em que eles aplicam o dinheiro. Isto dificulta a diversificação geográfica. Pois, eles podem não ter acesso tão fácil ao que a empresa vende no exterior. Os mesmos conseguem apenas ter uma visão de fora, não de um usuário ou mais próxima.

Dos 69 entrevistados, 66 acham importante, e desses, 40 atribuem muita importância. Acredito este ser um motivo bem forte para o Home bias ocorrer.

\subsubsection{Burocracia}

Pergunta: Burocracia? Ex.: Todo o processo de abrir conta, ligar para o exterior, relacionamento com a corretora. Sendo 5 um grande problema, 0 nenhum problema. 
Gráfico 8: Importância da Burocracia na decisão de compra de ações

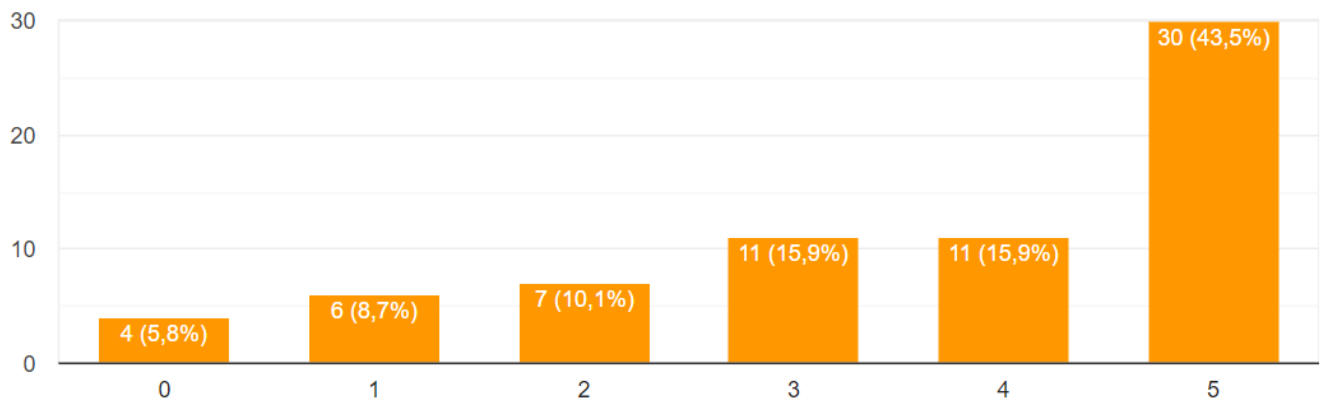

Fonte: Elaboração própria (2020).

Os resultados nos mostram que a burocracia também é considerada um grande complicador para os investidores se aventurarem em bolsas do exterior. 52 dos 69 entrevistados consideram o processo de abrir conta, escolher corretora, relacionamento com a corretora, pagamento de impostos, uma grande dificuldade.

A falta de informação, somada à burocracia, leva as pessoas a não buscarem diversificar geograficamente seus investimentos. O resultado foi o esperado, dado que essa foi a dificuldade mais citada no item 4.2.3.

\subsubsection{Proximidade da empresa}

Pergunta: O quão relevante para você, na hora de comprar uma ação, é estar próximo à empresa? Ex.: Algum conhecido trabalha nela ou você a acompanha há muito tempo. Sendo 5 muito relevante, 0 pouco.

Gráfico 9: Importância de estar próximo à Empresa ao Investir

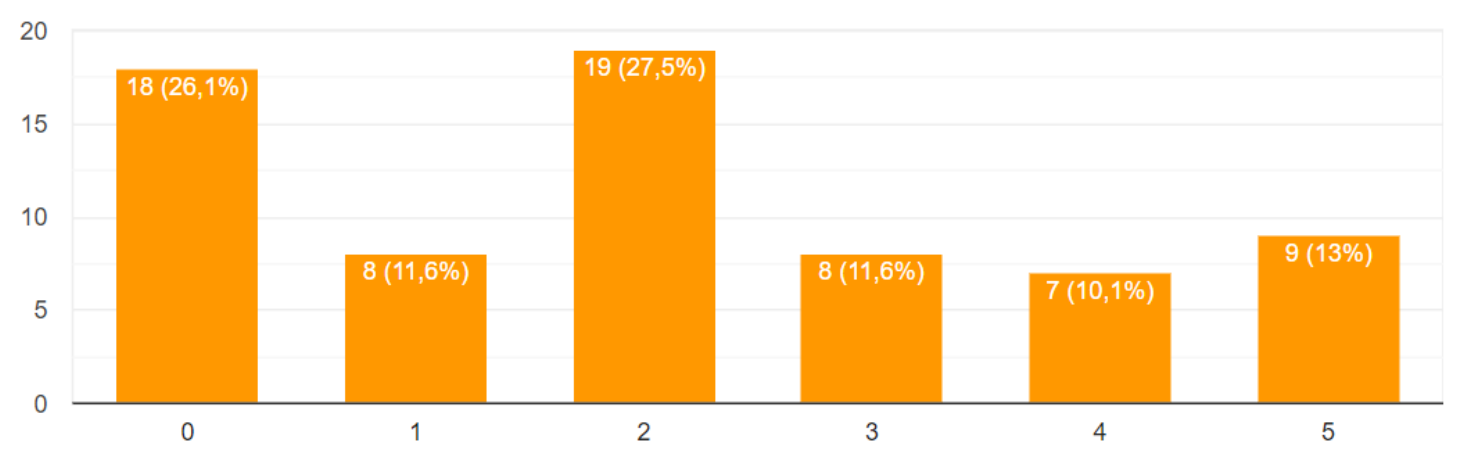

Fonte: Elaboração própria (2020). 
A maioria dos pesquisados achou pouco relevante a necessidade de o investidor estar "perto" da empresa, 45 de 69 investidores. Acompanhar a empresa por bastante tempo, ou ter proximidade, conhecidos, pessoas da família, alguém que pode dar mais informações, não foi apontado como algo tão influenciável na hora de comprar ações. O que é excelente para que as pessoas quebrem esse paradigma de só investir localmente.

\subsubsection{Home Bias}

Pergunta: Em relação ao conforto de investir na bolsa do seu país, de 0 a 5, qual o tamanho do seu DESCONFORTO em investir em ações de bolsas estrangeiras, em corretoras no exterior?

\section{Gráfico 10: Desconforto em Investir em Bolsas Estrangeiras}

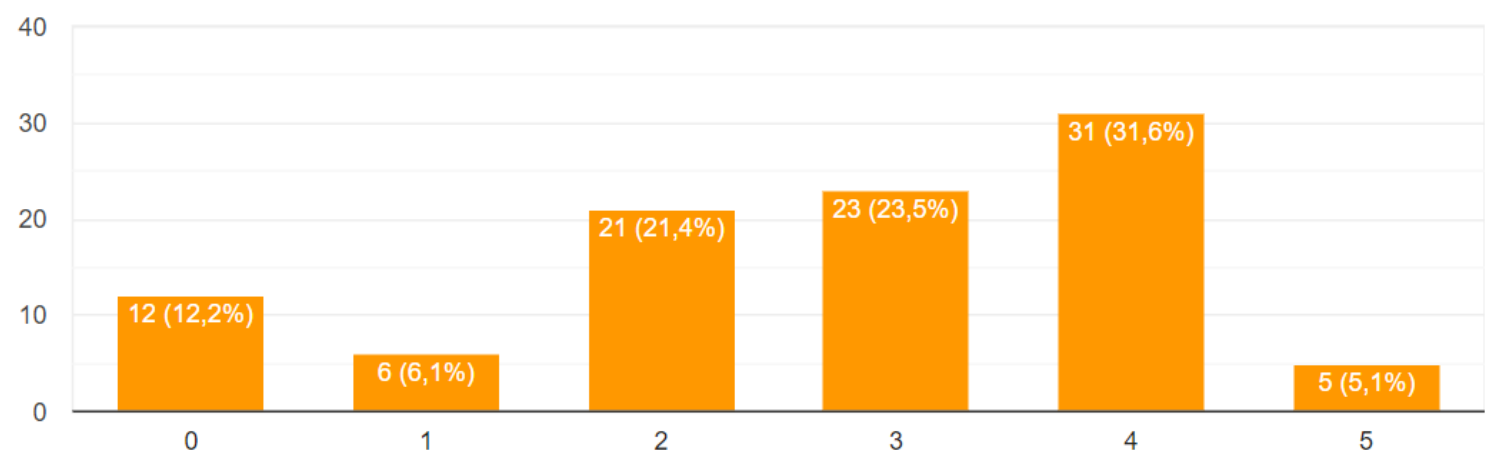

Fonte: Elaboração própria (2020).

A partir desses resultados, podemos dizer que existe um desconforto em comprar ações de bolsas estrangeiras. $60 \%$ dos 98 entrevistados votaram entre 3 e 5, mostrando-nos que, apesar dos investidores locais terem vontade de investir diversificando geograficamente, eles possuem desconfortos e inseguranças. Podemos perceber melhor isso com a tabela abaixo. 
Tabela 7: Desconforto x Vontade de investir em Bolsas Estrangeiras

\begin{tabular}{|l|l|l|l|l|l|l|}
\hline Desconforto/vontade & 0 & 1 & 2 & 3 & 4 & 5 \\
\hline Já invisto & 4 & 0 & 0 & 1 & 1 & 0 \\
\hline Tenho vontade & 7 & 4 & 17 & 12 & 19 & 4 \\
\hline Nunca pensei sobre & 1 & 2 & 3 & 9 & 9 & 1 \\
\hline Não quero & 0 & 0 & 1 & 1 & 2 & 0 \\
\hline
\end{tabular}

Fonte: Elaboração própria (2020).

35 dos 63 entrevistados (em torno de 56\%) que não investem ainda e têm vontade de investir se sentem bem desconfortáveis em aplicar em ações de outros mercados. Vemos ainda que 2 pessoas que já investem, ou seja, já passaram pela experiência, também possuem um certo desconforto. E então, perguntamos como os entrevistados classificariam esse desconforto, e obtivemos as seguintes respostas:

\section{Gráfico 11: Classificação do Desconforto}

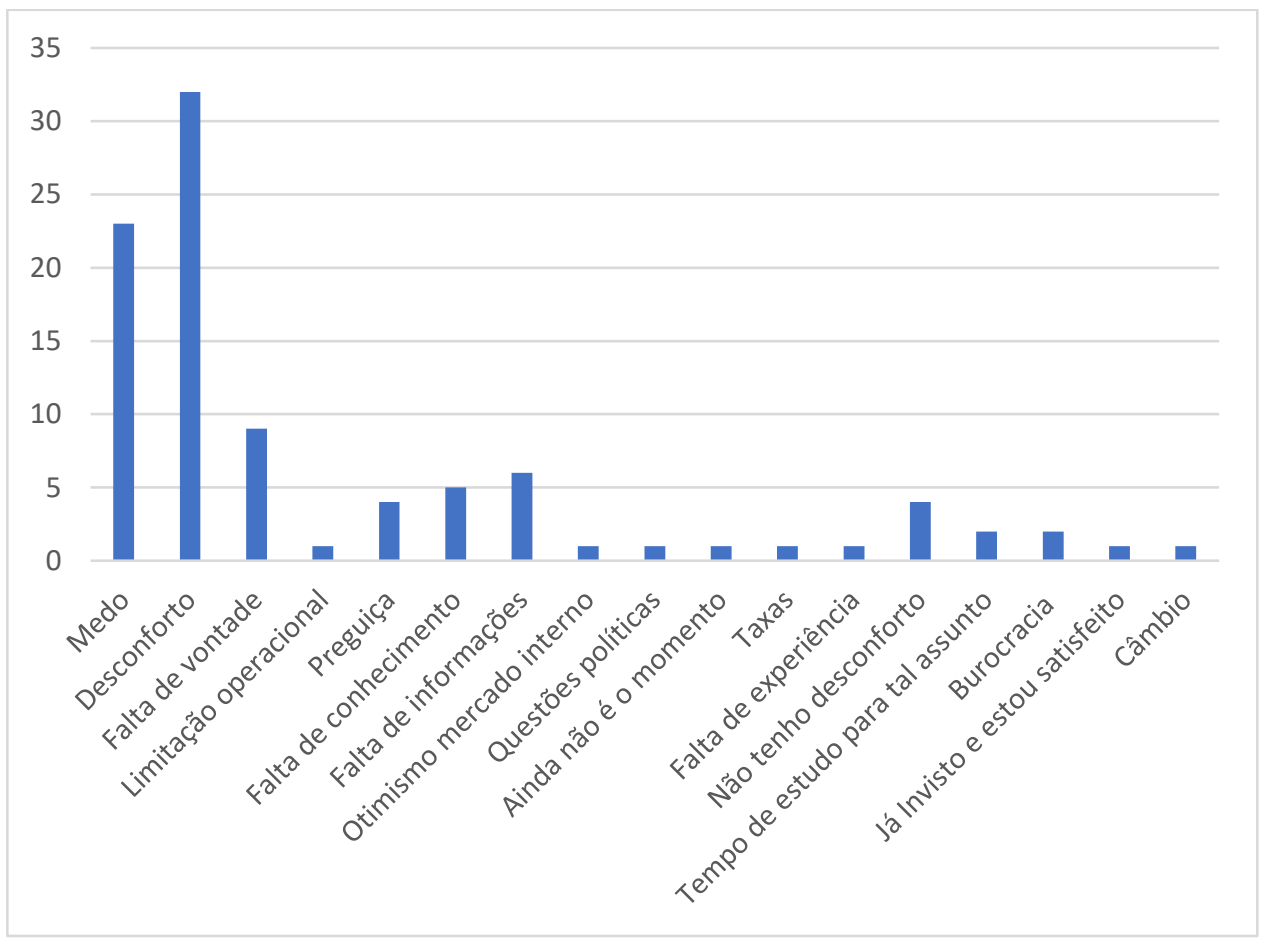

Fonte: Elaboração própria (2020). 
Portanto, podemos observar que, apesar da falta de informações e formas de acompanhar os investimentos em bolsas externas, os investidores brasileiros possuem medo, deconforto e insegurança em investir em ações no estrangeiro. Mesmo com essa "deficiência" de educação financeira que ocorre no Brasil, é possível enxergar o Home Bias.

Cada investidor possui suas dificuldades, crenças e formas de se comportar. Uns têm dificuldade com a língua, outros veem o mercado interno com grande otimismo, outros têm medo, outros acham que o mercado externo se resume a Estados Unidos. Entretanto, os resultados que a pesquisa sobre os Investidores da B3 nos passa é que a grande maioria não investe no exterior por questões de comodidade e familiaridade, assim sendo irracionais. 


\section{Conclusões}

O estudo teve como um dos seus objetivos constatar as diferenças entre os efeitos da diversificação setorial e geográfica para o risco de uma carteira de ativos. E a partir do estudo da covariância e da correlação, podemos dizer que comprar ações em diferentes bolsas tem maior efeito na diversificação do risco do que comprar ações de uma mesma bolsa de empresas de diferentes setores.

Assim, mostramos para os investidores da bolsa brasileira que eles estão perdendo oportunidades de investimentos, que poderiam acarretar em carteiras com maiores retornos e menores riscos. Isso ocorre por conta da tendência comportamental de evitar a compra de ações de empresas estrangeiras de outros mercados financeiros.

Ademais, o estudo ainda indicou oportunidades de investimentos no exterior para os investidores da B3, de construírem carteiras mais eficientes em relação a risco e retorno. Por exemplo, ao misturar ações da bolsa nacional com ações de empresas comercializadas em outras bolsas, como mostrou o Índice de Sharpe.

Fora isso, buscamos entender os motivos pelos quais essas pessoas estariam evitando este tipo de investimento em ativos internacionais. E, então, conseguimos constatar, através da pesquisa de campo, o que leva os investidores brasileiros a evitar a diversificação geográfica, evidenciando a ocorrência do chamado "Home Bias".

Logo, dado o resultado das duas pesquisas, podemos concluir que a diversificação - tanto setorial, quanto geográfica - diminui o risco não sistemático da carteira. Entretanto, a geográfica tem maior efeito. E cada investidor possui uma dificuldade e/ou um sentimento, pensamento sobre comprar ativos internacionais. As pessoas se comportam de formas diferentes diante da incerteza.

Neste sentido, foi possível enxergar aqueles pontos que foram apontados como razões para a existência do fenômeno do Home Bias na contextualização - otimismo no mercado interno, burocracia, língua, distância do mercado (dificuldade de monitoramento), conhecimento sobre a empresa, busca pela familiaridade, aversão ao risco e falta de informação - como relevantes. Cada um com o seu grau de importância.

Portanto, as evidências permitem afirmar que os investidores da B3 estariam sendo irracionais ao evitar aplicar seus recursos em ativos internacionais. 


\section{Referencial Bibliográfico}

Blog BTG Pactual Digital: Diversificação de Investimentos, 2017. Site: https://www.btgpactualdigital.com/blog/investimentos/diversificacao-de-investimentos.

DAMODARAN, A. Finanças corporativas aplicadas: Manual do usuário. Porto Alegre: Bookman, 2002.

DAMODARAN, A. Gestão Estratégica do Risco. Pearson Education, Inc., 2008.

FRANK, K. REILLY; KEITH, C. BROWN; LUCY, F. ACKERT; RICHARD DEAVES Behavioural Finance and Investment Analysis. Second Edition. Amsterdã, 2018.

G1: Copom faz novo corte e juro básico cai de 3,75\% para 3\% ao ano, 2020. Site: https://g1.globo.com/economia/noticia/2020/05/06/copom-faz-novo-corte-e-juro-basico-caide-375percent-para-3percent-ao-ano.ghtml

GRINBLATT, M.; KELOHARJU, M. How distance, language and culture influence stockholdings and trades. Journal of Finance 56. 2001.

HC investimentos: $\mathrm{O}$ que é índice de Sharpe?, 2011. Site: https://hcinvestimentos.com/2011/12/12/indice-de-sharpe/

Investing: Aeon Co., Ltd. (8267), 2019. Site: https://www.investing.com/equities/aeon-co.,-Itd.historical-data

Investing: Ambev SA (ABEV3), 2019. Site: https://www.investing.com/equities/ambev-pnhistorical-data

Investing: Cogna Educação (COGN3), 2019. Site: https://www.investing.com/equities/krotonon-nm-historical-data

Investing: Fleury SA (FLRY3), 2019. Site: https://www.investing.com/equities/fleury-on-nmhistorical-data

Investing: ICA Gruppen AB (ICAA), 2019. Site: https://www.investing.com/equities/hakoninvest-historical-data?cid $=25985$

Investing: Itaú Unibanco Holding SA (ITUB3), 2019. Site: https://www.investing.com/equities/Itaúunibanco-on-edj-n1-historical-data

Investing: JBS SA (JBSS3), 2019. Site: https://www.investing.com/equities/jbs-on-nmhistorical-data 
Investing: Koninklijke Ahold Delhaize NV (AD), 2019. Site: https://www.investing.com/equities/ahold-kon-historical-data Investing: Linx (LINX3), 2019. Site: https://www.investing.com/equities/linx-on-historical-data Investing: Lojas Americanas SA (LAME3), 2019. Site: https://www.investing.com/equities/lojas-americ-on-historical-data

Investing: Lojas Renner SA (LREN3), 2019. Site: https://www.investing.com/equities/lojasrenner-on-nm-historical-data

Investing: MRV engenharia e Participações SA (MRVE3), 2019. Site: https://www.investing.com/equities/mrv-on-nm-historical-data

Investing: Petróleo Brasileiro SA (PETR3), 2019. Site: https://www.investing.com/equities/petrobras-on-historical-data Investing: Picknpay (PIKJ), 2019. Site: https://www.investing.com/equities/picknpay-historicaldata

Investing: President Chain Store Corp (2912), 2019. Site: https://www.investing.com/equities/president-chai-historical-data Investing: TIM Participações SA (TIMP3), 2019. Site: https://www.investing.com/equities/timpart-s-a-on-nm-historical-data

Investing: Trent Ltd (TREN), 2019. Site: https://www.investing.com/equities/trent-historicaldata

Investing: Walmart Inc (WMT), 2019. Site: https://www.investing.com/equities/wal-martstores-historical-data

Investing: Woolworths (WOW), 2019. Site: https://www.investing.com/equities/woolworthslimited-historical-data

Investing: Yonghui Superstores Co Ltd (601933), 2019. Site: https://www.investing.com/equities/yonghui-stores-historical-data MBA em Gestão de Empreendimentos Turísticos: Estatística Aplicada ao Turismo, 2014. Site: https://slideplayer.com.br/slide/1604968/ 
Money Times: Apesar de estar no currículo, apenas 1\% dos brasileiros realmente fala ingles fluente, 2019. Site: https://www.moneytimes.com.br/apesar-de-estar-no-curriculo-apenas-1dos-brasileiros-realmente-fala-ingles-fluente/

Pro Educacional: Risco Sistmático e Não Sistemático, 2018. Site: https://proeducacional.com/ead/curso-cga-modulo-ii/capitulos/teoria-moderna-dascarteiras/aulas/aula-156/

RICARDO COELHO; PETER RICHMOND; STEFAN HUTZLER. A random-matrix-theorybased analysis of stocks of markets from different countries. World Scientific Publishing Company. Ireland, 2008.

ROSS, S.; WESTERFIELD, R. W.; JAFFE, J. E. Administração financeira. São Paulo: Atlas, 2009.

ROSS, S.; WESTERFIELD, R. W.; JAFFE, J. E. Administração financeira. São Paulo: Atlas, 2002.

Silva, N.D.; Malaquias, R.F.; Peixoto, F.M. Home Bias and Performance: a study with Brazilian mutual funds. Rev. Adm. UFSM, Santa Maria, v. 13, n. 1, p. 58-71, 2020

Suno Research: Aversão ao Risco: entenda como funciona a tolerância aos riscos nos investimentos, 2019. Site: https://www.sunoresearch.com.br/artigos/aversao-ao-risco/

Suno Research: Diversificação de investimentos: aprenda como fazer a sua, 2017. Site: https://www.sunoresearch.com.br/artigos/diversificacao/

Top Invest: risco de carteira , 2019. Site: https://www.topinvest.com.br/risco-de-carteira/ Trader Gráfico: Teoria de Carteiras - parte 2, 2008. Site: https://www.tradergrafico.com.br/www/newsletter/?Data=15/12/2008\&Email=convidado 
Apêndice: Planilha EXCEL com os cálculos financeiros

Consultar planilha em arquivo complementar: "carteira final. xIsx" 